\title{
Quantification of hydrologic impacts of climate change in a Mediterranean basin in Sardinia, Italy, through high-resolution simulations
}

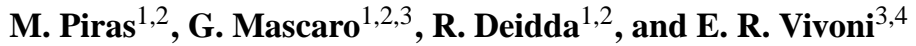 \\ ${ }^{1}$ Dipartimento di Ingegneria Civile, Ambientale ed Architettura, Università degli Studi di Cagliari, Cagliari, Italy \\ ${ }^{2}$ Consorzio Interuniversitario Nazionale per la Fisica dell' Atmosfere e dell'Idrosfere, Tolentino, Italy \\ ${ }^{3}$ School of Sustainable Engineering and the Built Environment, Arizona State University, Tempe, AZ, USA \\ ${ }^{4}$ School of Earth and Space Exploration, Arizona State University, Tempe, AZ, USA
}

Correspondence to: G. Mascaro (gmascaro@asu.edu)

Received: 25 June 2014 - Published in Hydrol. Earth Syst. Sci. Discuss.: 23 July 2014

Revised: 4 November 2014 - Accepted: 16 November 2014 - Published: 15 December 2014

\begin{abstract}
Future climate projections robustly indicate that the Mediterranean region will experience a significant decrease of mean annual precipitation and an increase in temperature. These changes are expected to seriously affect the hydrologic regime, with a limitation of water availability and an intensification of hydrologic extremes, and to negatively impact local economies. In this study, we quantify the hydrologic impacts of climate change in the Rio Mannu basin (RMB), an agricultural watershed of $472.5 \mathrm{~km}^{2}$ in Sardinia, Italy. To simulate the wide range of runoff generation mechanisms typical of Mediterranean basins, we adopted a physically based, distributed hydrologic model. The highresolution forcings in reference and future conditions (30year records for each period) were provided by four combinations of global and regional climate models, bias-corrected and downscaled in space and time (from $\sim 25 \mathrm{~km}, 24 \mathrm{~h}$ to $5 \mathrm{~km}, 1 \mathrm{~h})$ through statistical tools. The analysis of the hydrologic model outputs indicates that the RMB is expected to be severely impacted by future climate change. The range of simulations consistently predict (i) a significant diminution of mean annual runoff at the basin outlet, mainly due to a decreasing contribution of the runoff generation mechanisms depending on water available in the soil; (ii) modest variations in mean annual runoff and intensification of mean annual discharge maxima in flatter sub-basins with clay and loamy soils, likely due to a higher occurrence of infiltration excess runoff; (iii) reduction of soil water content and actual evapotranspiration in most areas of the basin; and (iv) a drop
\end{abstract}

in the groundwater table. Results of this study are useful to support the adoption of adaptive strategies for management and planning of agricultural activities and water resources in the region.

\section{Introduction}

Several studies using simulations of future climate robustly indicate the Mediterranean area as one of the regions of the world to be most severely affected by global changes. This area has in fact been classified by Giorgi (2006) as a primary hot spot most sensitive to climate change based on an index that combines variations in precipitation and air temperature from a multimodel ensemble of climate simulations. Specifically, the majority of climate projections agree in the prediction of an increase in mean temperature and a reduction in mean precipitation for the Mediterranean region. For example, climate simulations under the A1B emission scenario (Nakićeović et al., 2000; IPCC, 2007) predict a mean annual warming from 2.2 to $5.1^{\circ} \mathrm{C}$. Christensen et al. (2008) found that mean annual precipitation is expected to decrease between 4 and $27 \%$. Giorgi and Lionello (2008) provide a good synthesis of several climate simulations conducted in the Mediterranean region that summarize these main results.

Mediterranean watersheds are characterized by high spatial heterogeneity of terrain and surface properties. These features lead to a hydrologic response that is particularly sen- 
sitive to current climate variability, which is characterized by a strong seasonality and large interannual fluctuations, with alternations of dry and wet periods lasting several years. As a result, these basins are prone to the occurrence of hydrologic extremes, including drought periods (Hoerling et al., 2012) and floods and flash-floods (Delrieu et al., 2005; Borga et al., 2007; Silvestro et al., 2012). Variations in future climate are expected to further impact Mediterranean watersheds at various spatial and temporal scales (Frei et al., 2006; Beniston et al., 2007; Mariotti et al., 2008), as also demonstrated through observed data (Mariotti, 2010; Hoerling et al., 2012). This, in turn, is expected to affect important economic activities, especially those strongly dependent on water resources such as agriculture and tourism. For example, a future reduction in crop production is anticipated in southern Europe and Mediterranean regions due to decreasing water availability and degradation of soil and water quality (Olesen and Bindi, 2002; Falloon and Betts, 2010).

Given the high sensitivity of Mediterranean basins to climate variability and its socioeconomic impacts, a multi-institutional research project, named Climate-Induced Changes on the Hydrology of Mediterranean Basins (CLIMB), was funded by the 7th Framework Program of the European Union (Ludwig et al., 2010). The CLIMB project focused on seven study sites encompassing different conditions. An approach based on simulations of various climate and hydrologic models, analysis of environmental and economic data, field campaigns and stakeholder engagement was adopted to (i) reduce the uncertainty in the quantification of climate-induced changes on hydrological responses, and (ii) develop projections and tools to support planning and management of water resources and associated economic activities.

One of the CLIMB sites is the Rio Mannu basin (RMB, $472.5 \mathrm{~km}^{2}$ ) located in an agricultural area in Sardinia, Italy. This basin has experienced multiyear drought periods (the most recent during 1990-2000) that resulted in water restrictions for the agricultural and tourist sectors and led to substantial financial losses. Despite this, no extensive study has been devoted to evaluating the hydrological vulnerability of this and other Sardinian basins. In this paper, we provide a contribution to address this issue by quantifying the hydrologic response of the RMB to different climate change projections. For this aim, four bias-corrected climate forcings are first set up for a reference and a future period, using the best-performing combinations of global (GCM) and regional (RCM) climate models selected by Deidda et al. (2013). These climate forcings are used as input for the TIN-based Real-time Integrated Basin Simulator (tRIBS) hydrologic model, which was calibrated and validated with reasonable accuracy as illustrated in a previous study by Mascaro et al. (2013a). Since climate model outputs are provided at coarse spatial $(\sim 25 \mathrm{~km})$ and temporal (daily) scales while the hydrologic model requires hourly data, proper downscaling tools are applied to increase their spatiotemporal res- olution (up to $5 \mathrm{~km}, 1 \mathrm{~h}$ ). Hydrologic model outputs under the four climate scenarios, including time series and spatial maps, are then post-processed to (i) evaluate the impacts on water resources and hydrologic extremes, and (ii) investigate possible changes on the dominant physical processes in the basin.

While the general approach adopted here has been used by other studies (Abbaspour et al., 2009; Cayan et al., 2010; Liuzzo et al., 2010; Senatore et al., 2011; Montenegro and Ragab, 2012; Sulis et al., 2011, 2012; Camici et al., 2014; Tramblay et al., 2013), our methodology has novel contributions. First, most studies carry out hydrologic simulations at the daily scale. Here, a process-based model at subdaily (hourly) resolution is used to simulate the hydrologic processes typical of Mediterranean basins (Moussa et al., 2007), which are characterized by short response time and nonlinear rainfall-runoff transformation resulting from different runoff mechanisms (Piñol et al., 1997; Gallart et al., 2002; Beven, 2002). Second, procedures are applied to downscale bias-corrected climate model outputs to smaller spatial and temporal scales required for a reliable simulation of the hydrological processes in a medium-sized basin. These downscaling procedures are then distinct from the bias correction, which instead aims at correcting the large discrepancy between climate model outputs and observations of precipitation and temperature in the basin. Finally, the uncertainty associated with different climate models is taken into account by using four scenarios based on different combinations of GCMs and RCMs.

\section{Study area}

The Rio Mannu di San Sperate at Monastir basin (RMB) is a medium-sized watershed draining an area of $472.5 \mathrm{~km}^{2}$, located in Sardinia, Italy (Fig. 1). It is a representative basin of the Mediterranean region where the hydrologic response is affected by climate variability, with the occurrence of multiyear drought periods affecting agricultural activities. In this watershed, the Sardinian Agency for Research in Agriculture (AGRIS) manages an experimental farm of 436 ha, where hydrometeorological data are collected and productivity of different crops is monitored. The RMB contributes to the water supply system of Sardinia through a reservoir located in proximity of the outlet (Fig. 1c). Topography of the RMB is gentle, with a minimum, mean and maximum elevation of 66, 296 and $963 \mathrm{ma.s.l}$. (above sea level) and a mean slope of $17.3 \%$. The western and central parts of the basin are relatively flat, while a mountain range lies in the southeastern part. The climate is Mediterranean with a strong seasonality characterized by dry summers (June-August) and rainfall during the rest of the year having a mean number of rainy days per month between 6 and 12 days. Precipitation occurs almost always in form of rainfall with a climatological annual mean of $680 \mathrm{~mm}$. The annual average po- 

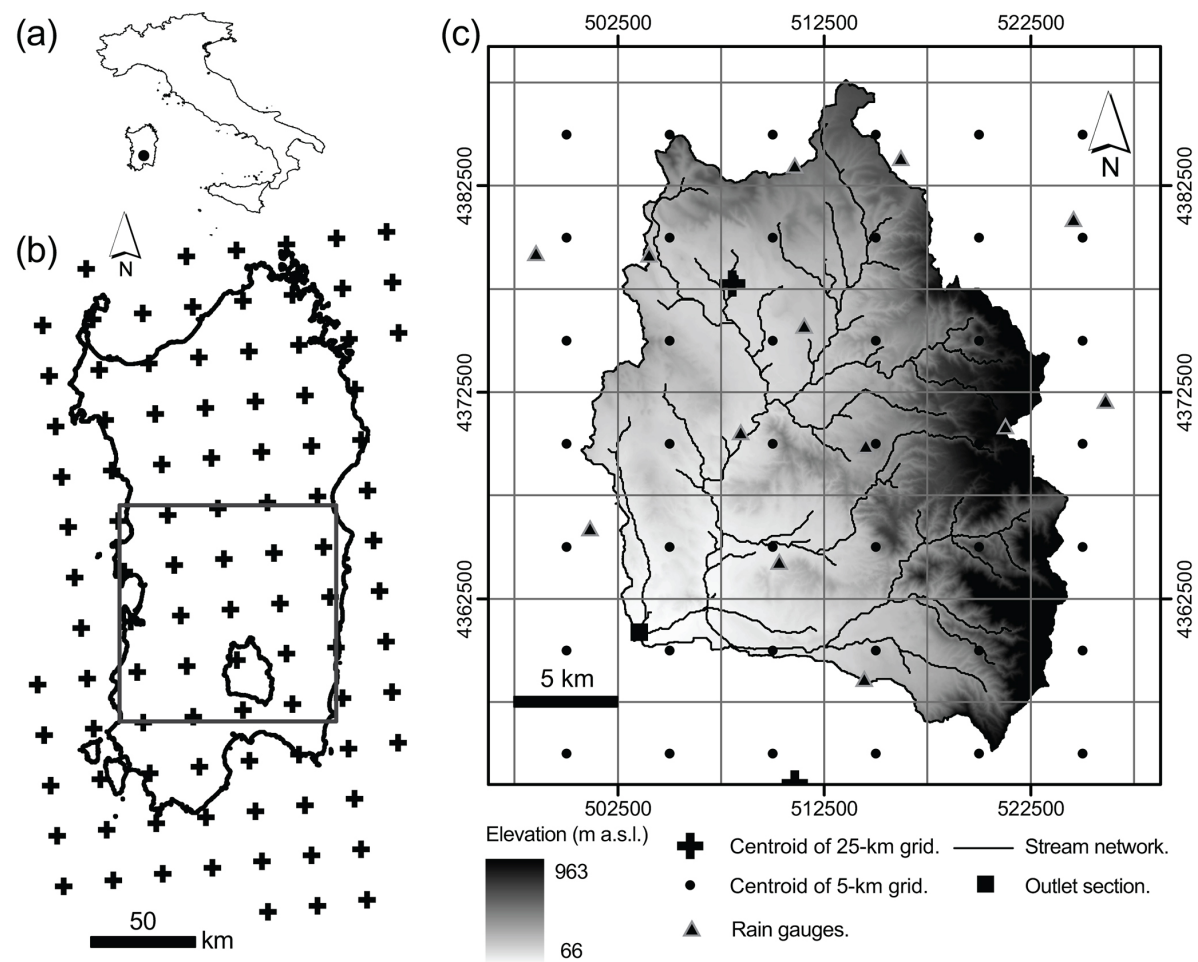

Figure 1. Location of the RMB within (a) Italy and (b) the island of Sardinia. (c) DEM of the RMB in UTM (universal transverse Mercator) coordinates. In (b) and (c), crosses are centroids of the $25 \mathrm{~km}$ grid of the RCMs, and the black square is the $104 \mathrm{~km} \times 104 \mathrm{~km}$ coarse-scale domain for the precipitation downscaling scheme. In (c), the circles are the centroids of the $5 \mathrm{~km}$ grid of the disaggregated precipitation products, and the triangles are the rain gages used to perform the local-scale bias correction.

tential evapotranspiration is $750 \mathrm{~mm}$ (Pulina, 1986). Streamflow is characterized by low flow conditions $\left(<1 \mathrm{~m}^{3} \mathrm{~s}^{-1}\right)$ throughout the year, with a few flood events mostly caused by fall and winter frontal systems (Chessa et al., 1999; Mascaro et al., 2013b). Land use information from the COoRdination de l'INformation sur l'Environnement (CORINE) project shows that agriculture $(\sim 48 \%)$ and sparse vegetation $(\sim 26 \%)$ are the dominant categories while other minor classes include olives, forests, pastures, vineyards and urban areas (Fig. 2a). Soil texture includes mainly six classes: clay loam-clay (37\%), sandy loam-loam (32\%) and sandy loam-sandy clay loam (20\%) (Fig. 2b).

\section{Data and methods}

The impacts on the hydrologic response due to changes in future climate were quantified as follows. Outputs of different combinations of GCMs and RCMs were processed to create four scenarios of hydrometeorological data in a reference (REF) time slice from 1971 to 2000 and a future (FUT) period from 2041 to 2070. Changes in hydrologic response in terms of availability of water resources and hydrologic extremes were quantified by comparing tRIBS outputs in REF and FUT periods. Procedures to create the climate forcing for the hydrologic simulations are discussed in Sect. 3.1, while the main features of the tRIBS model are discussed in Sect. 3.2.

\subsection{Generation of the climate forcing}

The procedure to create the high-resolution climate forcing in the REF and FUT periods can be summarized in four steps: (i) selection of GCM-RCM combinations; (ii) largescale bias correction of climate model outputs; (iii) disaggregation in space and time of precipitation $(P)$ and localscale bias correction; and (iv) computation of hourly potential evapotranspiration $\left(\mathrm{ET}_{0}\right)$ from daily minimum $\left(T_{\min }\right)$ and maximum $\left(T_{\max }\right)$ temperatures, as illustrated next.

\subsubsection{Selection of GCM-RCM combinations}

Deidda et al. (2013) evaluated the performance of 14 combinations resulting from the coupling of six GCMs with six RCMs from the ENSEMBLES project (http://ensembles-eu. metoffice.com) in some Mediterranean basins, including the RMB. The analysis was restricted for the future period to the A1B emissions scenario, because (i) this is commonly considered the most realistic, and (ii) the ENSEMBLES climate models have the most complete data set for this scenario. Model outputs at daily resolution in time and $0.22^{\circ}$ $(\sim 25 \mathrm{~km})$ in space (see the grid in Fig. 1b) were compared 
Table 1. List of the GCMs used as drivers of ENSEMBLES RCMs considered in this study together with corresponding climatological center and model, and acronyms adopted. The four GCM-RCM combinations used in this study are ECH-RCA, ECH-REM, ECH-RMO and HCH-RCA.

\begin{tabular}{|c|c|c|}
\hline & Climatological center and model & Acronym \\
\hline \multirow[t]{2}{*}{$\begin{array}{l}\text { Global climate } \\
\text { models, GCMs }\end{array}$} & $\begin{array}{l}\text { Hadley Centre for Climate Prediction, Met Office, UK } \\
\text { HadCM3 Model }\end{array}$ & $\mathrm{HCH}$ \\
\hline & $\begin{array}{l}\text { Max Planck Institute for Meteorology, Germany } \\
\text { ECHAM5/MPI Model }\end{array}$ & $\mathrm{ECH}$ \\
\hline \multirow[t]{3}{*}{$\begin{array}{l}\text { Regional climate } \\
\text { models, RCMs }\end{array}$} & $\begin{array}{l}\text { Swedish Meteorological and Hydrological Institute (SMHI), } \\
\text { Sweden RCA Model }\end{array}$ & $\mathrm{RCA}$ \\
\hline & $\begin{array}{l}\text { Max Planck Institute for Meteorology, Hamburg, Germany } \\
\text { REMO Model }\end{array}$ & REM \\
\hline & $\begin{array}{l}\text { Koninklijk Nederlands Meteorologisch Instituut (KNMI), } \\
\text { Netherlands RACMO2 Model }\end{array}$ & RMO \\
\hline
\end{tabular}

(a)

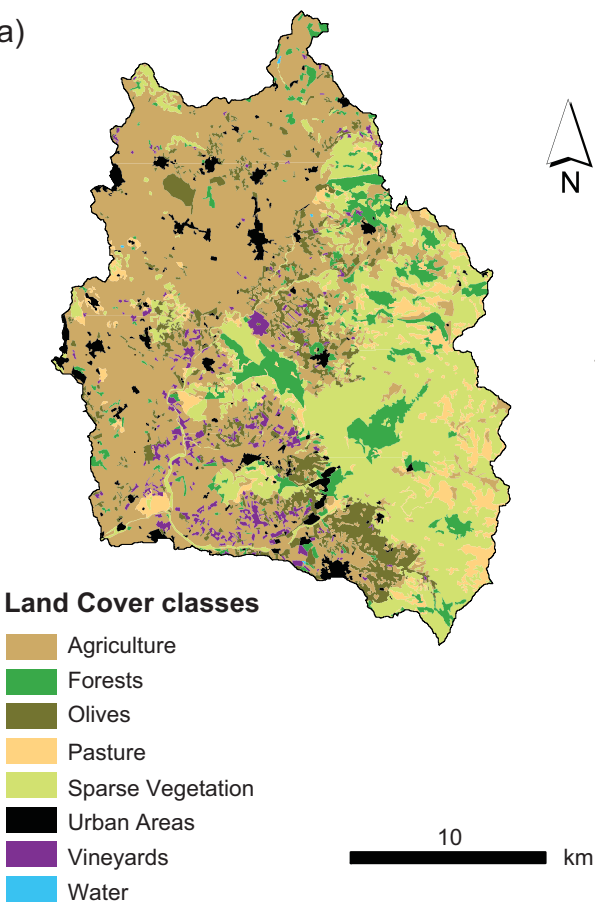

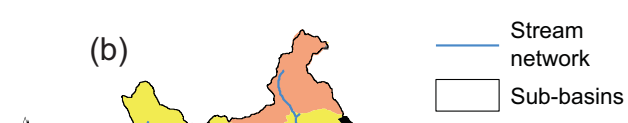

Soil texture classes
Sandy clay loam - Clay
Sandy loam- Sandy clay loam
Sandy loam
Clay loam - Clay
Urban
Sandy loam - Loam

Figure 2. (a) Land cover and (b) soil texture maps used as input for the tRIBS model. In (b), the boundaries of 20 sub-basins are also reported along with the stream network.

against historical data of daily $P$ and daily mean, minimum and maximum temperature $(T)$ from the CRU (climate research unit) E-OBS data set (Haylock et al., 2008), available on the same spatial grid. In the RMB, four combinations of two GCMs and three RCMs were found by Deidda et al. (2013) to be the most accurate: ECH-RCA, ECHREM, ECH-RMO and HCH-RCA (see Table 1 for model descriptions and acronyms). The selection of these GCMRCM combinations, hereafter simply referred as selected climate models (CMs), also obeys the criterion of having at least two RCMs nested in the same GCM and two different GCMs forcing the same RCM. The use of four climate sce- narios permits characterizing, to a certain extent, the uncertainties associated with different climate models and possible model combinations.

\subsubsection{Large-scale bias correction}

Most climate models display some level of deficiencies in reproducing climatological features and seasonality in large basins (Lucarini et al., 2007, 2008; Hasson et al., 2013, 2014). In relatively small watersheds, these deficiencies are exacerbated. To reduce these well-known discrepancies and better reproduce the observed seasonal statistics, a large- 
scale bias correction of $P$ and $T$ fields predicted by the considered CMs was applied using the E-OBS data set. For this, the daily translation method was applied as it has demonstrated skill in prior studies (Wood et al., 2004; Maurer and Hildago, 2008; Sulis et al., 2012). The method is based on computing the monthly cumulative distribution functions (CDFs) of observed $\left(F_{\text {obs }}\right)$ and simulated $\left(F_{\text {sim }}\right)$ daily variables. For a given daily output variable of a climate model, $x$, the unbiased value, $x^{*}$, is obtained as $x^{*}=F_{\text {obs }}^{-1}\left[F_{\text {sim }}(x)\right]$, where $F_{\text {obs }}^{-1}$ is the inverse of $F_{\text {obs }}$. To reproduce the seasonal cycles, $F_{\text {obs }}$ and $F_{\text {sim }}$ functions were derived on a monthly basis, i.e., pooling together all daily observations (or simulated records) for each month. The procedure was applied to the daily $P$ and the daily mean, minimum and maximum $T$. In this effort, $T$ was also corrected to account for the different elevations adopted by CMs and E-OBS via a spatial and dynamic lapse rate.

\subsubsection{Precipitation downscaling and local-scale bias correction}

One source of uncertainty of climate models is related to the smoothing effect induced by their coarse spatial $(\sim 25 \mathrm{~km})$ and temporal (24 h) resolution (Wilby and Wigley, 1997; Maraun et al., 2010; Bardossy and Pegram, 2011). This is especially true for $P$, which is characterized by high intermittency and strong fluctuations in space and time, also affected by local orographic effects. To reproduce this feature, we used the precipitation downscaling technique based on a multifractal model (Space-Time Rainfall, STRAIN) that is able to recreate the scale invariance and multifractal properties of precipitation fields observed from coarse to small spatiotemporal scales (Deidda, 1999, 2000). This is achieved by means of a stochastic generator of multiplicative multifractal cascades, whose parameters can be derived from the large-scale rainfall amount, $R\left(\mathrm{~mm} \mathrm{~h}^{-1}\right)$, according to empirical calibration relations.

For the RMB, Mascaro et al. (2013a) calibrated the algorithm with rainfall observations at $1 \mathrm{~min}$ resolution of 204 gages, collected in the period 1986-1996 in the coarse spatial domain of $104 \times 104 \mathrm{~km}^{2}$ shown in Fig. 1b. A total of 800 precipitation events were used to estimate the model parameters and identify the calibration relations as a function of $R$ for our study area. As described in detail in Mascaro et al. (2013a), two tests were conducted to validate the downscaling method. First, the model capability to capture the small-scale rainfall distribution within the coarse-scale domain was evaluated by visually comparing observed and synthetic empirical cumulative distribution functions for each rainfall event. An example of this comparison is provided in Mascaro et al. (2013a; Fig. 6), which shows relatively good skill of the downscaling routine. A second validation was carried out specifically on the study basin, by comparing observed and simulated daily mean areal precipitation (MAP) from 1925 to 1935 . In this period, discharge data are available to calibrate and validate the hydrologic model (see Sect. 3.2) and rainfall observations were only collected at daily resolution. For each rainy day, the downscaling model was applied from the coarse to the fine resolution generating an ensemble of 50 disaggregated fields. The observed daily MAP in the basin was calculated by applying Thiessen polygons to the observations of 13 available gages, and the simulated MAP was derived by aggregating the synthetic grids at daily resolution and computing the spatial basin average. The root mean square error (RMSE) and bias between the observed MAP and the ensemble average from the downscaling model were then calculated. As reported in Mascaro et al. (2013a; Table 7), the RMSE has little interannual variability (average value of $4.38 \mathrm{~mm}$ ), while the bias is negative (mean of $-0.89 \mathrm{~mm}$ ), indicating that the downscaling procedure tends to slightly underestimate the observed MAP (less than $10 \%$ ).

In this study, the downscaling routine was applied by (i) aggregating the bias-corrected daily $P$ outputs of the CMs in the coarse spatial domain to compute $R$, (ii) using the RMB calibration relations to derive parameters conditioned on $R$, and (iii) applying STRAIN to downscale $R$ to $5 \mathrm{~km}$ and $1 \mathrm{~h}$ resolution. The disaggregated fields were also corrected for orographic effects using the elevation modulation function described by Badas et al. (2006). In principle, the statistically based disaggregation technique requires the generation of an ensemble of $P$ downscaled fields, each representing an equally probable realization of the coarse condition. For example, Mascaro et al. (2013a) generated an ensemble of $50 P$ downscaled members to calibrate and validate the tRIBS model. In this study, we only created a single disaggregated realization for each selected CM for two main reasons. First, climate models do not reproduce weather evolution in time according to deterministic rules, but rather reproduce the statistical peculiarity of the climatic features (Lucarini, 2008). In other words, a one-to-one correspondence between an observation and a climate model simulation does not exist for a certain day. Second, the multidecadal length of the REF and FUT periods (30 years) is large enough to assure that the use of a single disaggregated member is able to capture a large portion of the small-scale rainfall variability occurring within each time slice.

After the disaggregation, a last procedure for local-scale bias correction of $P$ was applied to correct residual biases mainly due to the coarseness of the rain gage network used for the E-OBS data set (Haylock et al., 2008), which may fail to reproduce the local features of $P$ fields. The procedure is illustrated in Fig. 3. The climatological monthly average of the MAP in the RMB was first calculated using data observed by 13 gages within the catchment over the period 1951-2008. In parallel, the same variable was computed for the disaggregated fields from all selected CMs in the same period. The ratio between observed and simulated mean monthly MAP was then used as a correction on the downscaled $P$ fields to eliminate the residual bias. 


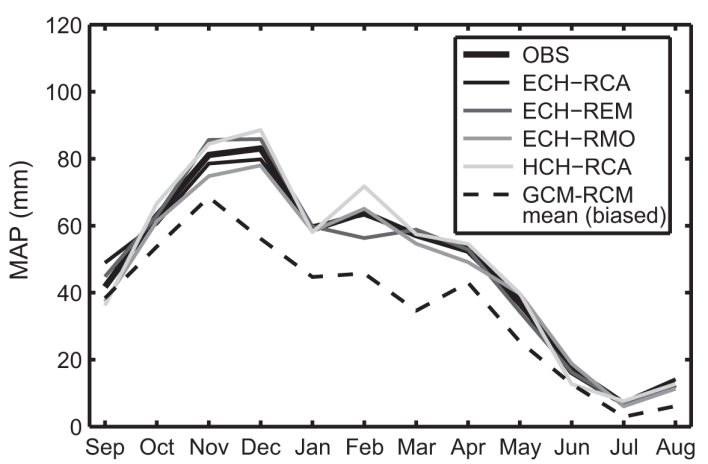

Figure 3. Illustration of the local-scale bias correction. Black line: climatological monthly average of the MAP in the RMB observed by 13 rain gages over 1951-2008. Black dashed line: MAP averaged across the four CMs during the same period before the bias correction. Gray shades, continuous lines: MAP of the four CMs after removing the bias.

\subsubsection{Computation of potential evapotranspiration}

For each $\mathrm{CM}$, we estimated the gridded $\mathrm{ET}_{0}$ at hourly resolution starting from the bias-corrected daily $T_{\min }$ and $T_{\max }$. For this purpose, the $T$ fields at $\sim 25 \mathrm{~km}$ resolution were first interpolated in the same $5 \mathrm{~km}$ grid used for $P$ as in Liston and Elder (2006), and then corrected for elevation variations of the $5 \mathrm{~km}$ grid using a dynamic lapse rate. Then, the downscaling technique proposed by Mascaro et al. (2013a) was applied to derive the maps of hourly $\mathrm{ET}_{0}$ from $T_{\min }$ and $T_{\max }$. The method requires an estimate of the daily $\mathrm{ET}_{0}$ by applying the Hargreaves formula with $T_{\min }$ and $T_{\max }$ and a linear correction to derive the value returned by the Penman-Monteith equation. Next, dimensionless functions that reproduce, for each month, the subdaily variability of $\mathrm{ET}_{0}$ are used to derive the hourly $\mathrm{ET}_{0}$ from the daily estimate. The procedure was calibrated and tested in the RMB using meteorological data (required to apply the Penman-Monteith formula) observed in one station over 1995-2010. To validate the method, we calculated the RMSE and bias between (i) the hourly $\mathrm{ET}_{0}$ computed using the Penman-Monteith formula and (ii) the hourly $\mathrm{ET}_{0}$ obtained with the disaggregation method starting from $T_{\min }$ and $T_{\min }$. Results show that, despite that the downscaling procedure slightly underestimates the hourly $\mathrm{ET}_{0}$ (negative mean bias of $-0.010 \mathrm{~mm} \mathrm{~h}^{-1}$ ), performances are overall fairly good, as indicated by the low RMSE (mean of $\left.0.030 \mathrm{~mm} \mathrm{~h}^{-1}\right)$. More details are provided by Mascaro et al. (2013a).

\subsection{The hydrologic model}

tRIBS is a physically based, distributed hydrologic model that is able to continuously simulate the coupled water and energy balance (Ivanov et al., 2004a, b). Terrain is represented through triangulated irregular networks (TINs) used to discretize the domain into Voronoi polygons. The use of
TINs allows for computational savings as compared to gridbased models due to the multiresolution domain representation (Vivoni et al., 2004, 2005). This feature is crucial for the feasibility of multidecadal hydrologic simulations carried out in climate change studies. The spatially distributed hydrologic response is reproduced by solving equations of the water and energy fluxes in each Voronoi polygon. In tRIBS, several hydrologic processes are represented, including canopy interception, infiltration and soil moisture redistribution, lateral water movement in the unsaturated and saturated zones, evaporation from bare soil and wet canopies, plant transpiration, overland flow in the hillslopes, and routing in the stream channel. The infiltration scheme allows for several configurations of soil moisture in the unsaturated and saturated zones. As a result, runoff generation is possible via four mechanisms: saturation excess, occurring when the single domain element is fully saturated from below; infiltration excess, occurring when the element is saturated from above by a high-intensity rainfall; perched return flow, occurring as lateral flow on the surface of a cell from a saturated layer in an upslope element; and groundwater exfiltration, occurring as lateral redistribution in the phreatic aquifer. As a result, this model has the capability to represent the strongly nonlinear rainfall-runoff relation typical of Mediterranean basins. The specific treatment of each process is described in detail by Ivanov et al. (2004a).

Model equations are parameterized through lookup tables and related spatial maps of soil texture and land cover. Precipitation can be provided as point time series or spatial grids. This last alternative is used in this study to force the model with gridded downscaled fields, as described in Sect. 3.1.3. Computing actual evapotranspiration $\left(\mathrm{ET}_{\mathrm{a}}\right)$ and its components requires estimating $\mathrm{ET}_{0}$. This can be performed by applying the Penman-Monteith equation with meteorological data or by forcing the model with $\mathrm{ET}_{0}$ computed offline, either in point or grid format. Again, this last alternative is used in this study to provide downscaled $\mathrm{ET}_{0}$ as described in Sect. 3.1.4. $\mathrm{ET}_{\mathrm{a}}$ is then estimated as a fraction of $\mathrm{ET}_{0}$ based on the available soil moisture using a piecewiselinear equation (Mahfouf and Noilhan, 1991; Ivanov et al., 2004a). Model outputs include time series of discharge at any location in the stream network and spatial maps of hydrologic state variables and fluxes (e.g., evapotranspiration, soil water content at different depths, ground water table position) at specified times or integrated over defined periods.

The model has been previously used in the areas of hydrometeorology (Mascaro et al., 2010; Moreno et al., 2013), climate change (Liuzzo et al., 2010) and ecohydrology (Mahmood and Vivoni, 2014). Recently, Mascaro et al. (2013a) calibrated and validated tRIBS in the RMB against streamflow data. A TIN with 171078 nodes was derived from a $10 \mathrm{~m}$ digital elevation model (DEM), retaining $3.6 \%$ of the DEM nodes and resulting in a vertical accuracy of $3 \mathrm{~m}$. Vegetation parameters, involved in the processes of rainfall interception and estimation of $\mathrm{ET}_{\mathrm{a}}$, have been derived for the 
Table 2. Mean annual values of MAP, $T$ and $Q$ in the RMB in REF and FUT periods with relative changes for each CM. The mean and standard deviation (SD) are also reported.

\begin{tabular}{|c|c|c|c|c|c|c|c|c|c|}
\hline \multirow{2}{*}{$\begin{array}{l}\text { Climate } \\
\text { model } \\
\text { combination }\end{array}$} & \multicolumn{3}{|c|}{$\begin{array}{c}\text { Mean annual } \\
\text { MAP }\end{array}$} & \multicolumn{3}{|c|}{$\begin{array}{c}\text { Mean annual } \\
T\end{array}$} & \multicolumn{3}{|c|}{$\begin{array}{c}\text { Mean annual } \\
Q\end{array}$} \\
\hline & $\begin{array}{r}\mathrm{REF} \\
(\mathrm{mm})\end{array}$ & $\begin{array}{r}\text { FUT } \\
(\mathrm{mm})\end{array}$ & $\begin{array}{r}\triangle \mathrm{MAP} \\
(\%)\end{array}$ & $\begin{array}{r}\mathrm{REF} \\
{ }^{\circ} \mathrm{C}\end{array}$ & $\begin{array}{r}\text { FUT } \\
{ }^{\circ} \mathrm{C}\end{array}$ & $\begin{array}{r}\Delta T \\
{ }^{\circ} \mathrm{C}\end{array}$ & $\begin{array}{r}\mathrm{REF} \\
(\mathrm{mm})\end{array}$ & $\begin{array}{r}\text { FUT } \\
(\mathrm{mm})\end{array}$ & $\begin{array}{l}\Delta Q \\
(\%)\end{array}$ \\
\hline ECH-RCA & 570.93 & 502.81 & -11.93 & 16.85 & 18.72 & 1.87 & 107.39 & 71.90 & -33.05 \\
\hline ECH-REM & 559.71 & 519.18 & -7.24 & 16.77 & 18.68 & 1.91 & 86.74 & 71.87 & -17.14 \\
\hline ECH-RMO & 542.80 & 487.87 & -10.12 & 16.83 & 18.72 & 1.89 & 91.30 & 67.87 & -25.66 \\
\hline $\mathrm{HCH}-\mathrm{RCA}$ & 575.06 & 453.19 & -21.19 & 16.52 & 19.59 & 3.08 & 107.96 & 53.71 & -50.24 \\
\hline Mean & 562.13 & 490.76 & -12.70 & 16.74 & 18.93 & 2.18 & 98.35 & 66.34 & -32.55 \\
\hline SD & 14.42 & 28.12 & 6.03 & 0.15 & 0.44 & 0.60 & 10.93 & 8.63 & 14.07 \\
\hline
\end{tabular}

land cover classes in Fig. 2a, based on values published in literature for similar land cover classes. The model was calibrated for 1 year (1930) and validated for 2 years (19311932), where daily discharge data collected by the Italian Hydrologic Survey were judged to have the highest quality. To identify robust model parameters while using a relatively short record of observations, we selected a wet year (total annual runoff of $183 \mathrm{~mm}$ ) with several flood events for calibration and 2 dry years (annual runoff of 76 and $71 \mathrm{~mm}$ ) with a few floods for validation. Since in the period 1930-1932 hydrometeorological data include rainfall data at daily resolution and daily $T_{\min }$ and $T_{\max }$, the downscaling procedures previously illustrated were used to create the high-resolution forcings. Despite the presence of several uncertainty sources, Mascaro et al. (2013a) showed adequate performances in the RMB for the tRIBS model, which is used here with the same parameterization.

\section{Results and discussion}

In this section, we first analyze the monthly variability of the basin-averaged $P$ and $T$ fields with the goal of highlighting the main climatological differences between the REF and FUT periods. Subsequently, we present results of the hydrologic simulations forced with the disaggregated $P$ and $\mathrm{ET}_{0}$. Specifically, the changes on stream discharge $(Q)$ are evaluated, focusing on both water resources availability and hydrologic extremes. Finally, variations in evapotranspiration $\left(\mathrm{ET}_{\mathrm{a}}\right)$, soil water content (SWC), and ground water level are explored.

\subsection{Changes in climate forcing}

Figure 4 reports different features of mean monthly variability of basin-averaged $P$ grids for the four CMs in the REF and FUT periods: MAP (Fig. 4a, b), number of rainy days $(N$; Fig. 4c, d), and mean precipitation intensity in rainy days ( $I$; Fig. 4e, f). In the left panels, the bars represent the mean \pm standard deviation across the four CMs of the 30- year monthly average of each variable. Note that the months are ordered according to the water year. For each CM, the relative monthly changes $\Delta \alpha(\%)$ from REF to FUT, computed by the following Eq. (1) for a generic variable $\alpha$, are plotted in the right panels:

$\Delta \alpha=\frac{\alpha_{\mathrm{FUT}}-\alpha_{\mathrm{REF}}}{\alpha_{\mathrm{REF}}} \cdot 100$,

where $\alpha_{\mathrm{FUT}}$ and $\alpha_{\mathrm{REF}}$ are the 30-year monthly mean of $\alpha$ in FUT and REF, respectively. Equation (1) is used in this paper for all variables, except for $T$ for which the changes are calculated through the simple difference between FUT and REF.

Figure 4a shows that MAP is expected to decrease in FUT in all months, except in winter (December-February) where mean values are similar. Negative $\triangle \mathrm{MAP}$ values are predicted by all combinations in September, November, March, April, and May, while in the other months the sign and magnitude of $\triangle$ MAP vary among the four combinations, even significantly (e.g., October and December), suggesting higher uncertainty in climate predictions (Fig. 4b). The mean annual MAP in REF and FUT periods and the relative changes are reported in Table 2 for each combination: we can observe that the four CMs predict a decrease in annual precipitation from $-7 \%$ (ECH-REM) to $-21 \%$ (HCH-RCA). These results are consistent with a number of studies that analyzed climate projections in the Mediterranean region under the A1B scenario (e.g., IPCC, 2007; Giorgi and Lionello, 2008; Senatore et al., 2011).

Similarly to MAP, $N$ is expected to decrease in FUT over the year except for winter, where no significant variations are expected (Fig. 4c). Changes in $N$ are similar for the four $\mathrm{CMs}$, indicating lower model uncertainty in predicting rainfall occurrence (Fig. 4d). The projections for the mean precipitation intensity $(I)$ are instead characterized by high variability over the year and across the combinations. Figure $4 \mathrm{e}$ shows that higher $I$ is predicted in FUT during the months with larger total precipitation (from October to December), and most of the summer (June and July). The rainfall inten- 

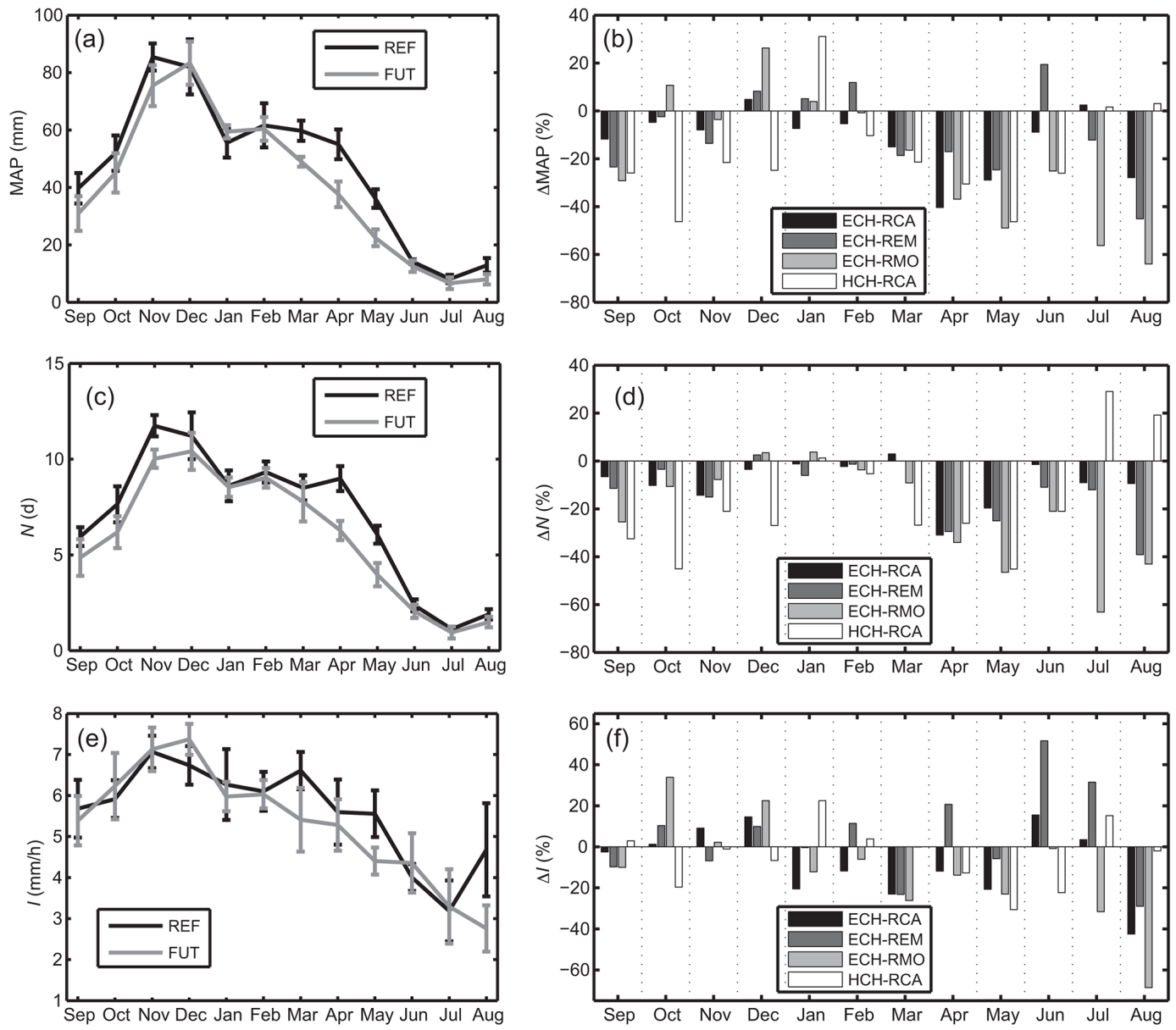

Figure 4. (a) Mean monthly MAP in the RMB in REF (black) and FUT (gray). Bars are mean \pm standard deviation across the CMs. (b) Relative change between FUT and REF periods in mean monthly MAP ( $\triangle \mathrm{MAP}$ ). (c) and (d) same as (a) and (b), but for the mean monthly $N$. (e) and (f) same as (a) and (b), but for the mean monthly $I$.

sity in FUT will be lower from January to May and in August and September. Figure $4 \mathrm{f}$ shows that sign and magnitude of $\Delta I$ are different in each month, highlighting a large uncertainty across the CMs. Since rainfall intensity is a crucial variable influencing runoff, this underlines the importance of using multiple combinations of GCMs and RCMs to account for climate model uncertainty in simulating hydrologic responses.

The mean monthly $T$ in REF and FUT periods is reported in Fig. 5a, while the relative changes $(\Delta T)$ are shown in Fig. 5b. As found in previous works (e.g., Giorgi and Lionello, 2008), the uncertainty in the prediction of future $T$ is considerably reduced as compared to $P$. All scenarios show a future increase of $T$ for all months with a low standard deviation among the combinations. Higher $\Delta T$ are expected in summer, with an average yearly variation from $1.87^{\circ} \mathrm{C}$ (ECH-RCA) to $3.08^{\circ} \mathrm{C}$ (HCH-RCA); see Table 2 for more details. As for $P$, the HCH-RCA combination predicts the largest variations in $T$. Overall, the monthly changes in $P$ and $T$ predicted by the CMs are very similar to the forcing used in another Mediterranean climate change study carried out by Senatore et al. (2011) in a watershed in southern Italy.

\subsection{Changes in stream discharge and runoff mechanisms}

The hourly gridded $P$ and $\mathrm{ET}_{0}$ from the four selected CMs were used to force the tRIBS model. A spin-up interval of 2 years was adopted before each 30-year run, totaling 256 years of simulation. This computational effort was carried out using the parallelized version of tRIBS (Vivoni et al., 2011), which took $880 \mathrm{~h}$ of CPU time over 64 processors. Model outputs including time series at distributed locations and spatial maps of hydrologic fluxes and state variables were postprocessed to quantify the changes from REF to FUT periods. Figure 6 presents results for the mean monthly $Q$ at the RMB outlet, according to Eq. (1). Despite no significant variation in MAP is anticipated during winter, $Q$ is predicted to diminish in FUT for all months (Fig. 6a) and by all scenarios (Fig. 6b). A slightly positive $\Delta Q$ is only 

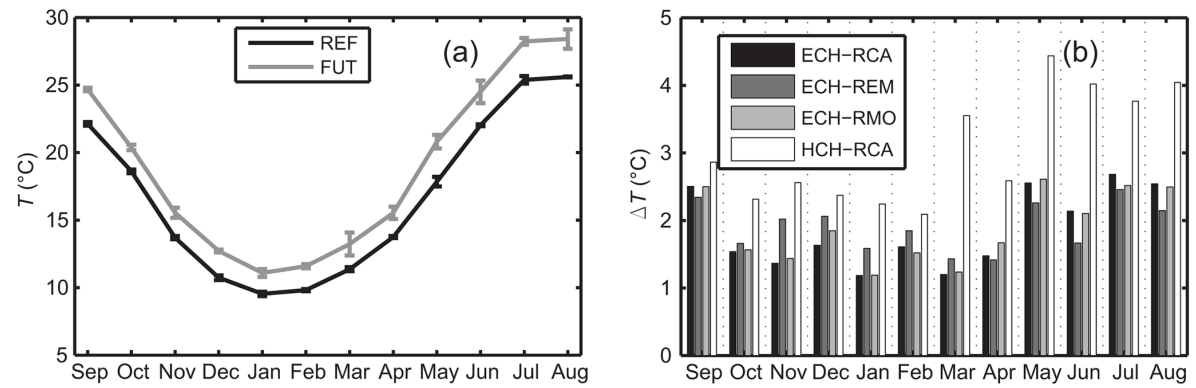

Figure 5. Same as Fig. 4, but for the mean monthly $T$.
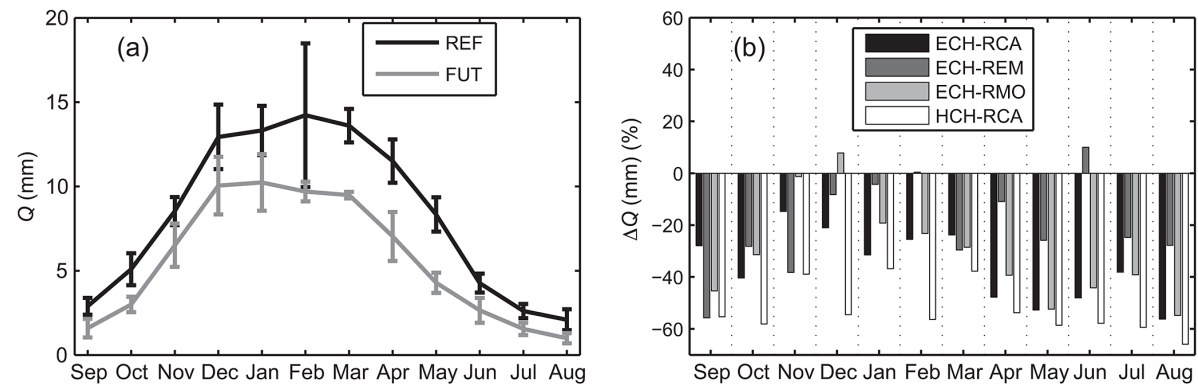

Figure 6. Same as Fig. 4, but for the mean monthly $Q$ at the RMB outlet.

found in December and June in one of the combinations. Note that the decrease of $Q$ in months with little variation in $P$ can be mostly ascribed to the diminution of the runoff portion due to groundwater exfiltration occurring throughout the year, as better illustrated below. Table 2 shows the mean annual changes, which range from $-17 \%$ (ECH-REM) to $-50 \%$ (HCH-RCA). Note that the different percentages observed for each CM are related to the decrease in $P$.

The change in mean annual $Q$ was further analyzed using the streamflow time series for the 20 sub-basins shown in Fig. $2 b$ (sub-basin 20 refers to the entire RMB). The terrain, soil texture and land cover characteristics of the sub-basins are summarized in Table 3 . The relation between $\Delta Q$ and the contributing area $\left(A_{\mathrm{c}}\right)$ is shown in Fig. 7a, in terms of mean and standard deviation across the CMs. Results indicate the presence of two groups of sub-basins. The first includes five subwatersheds labeled as 1-4 and 9, with a slightly positive mean $\Delta Q(\sim+8 \%)$ and higher standard deviation that suggests larger uncertainty due to the different climate forcings. These sub-basins are located in the northwestern portion of the RMB and are characterized by a relatively low slope (mean of $\sim 8 \%$ ), dominance of clay loam-clay soil texture $(>77 \%)$ and agricultural land use $(>71 \%)$. The second group includes all the other sub-basins and displays a significant drop of $Q$ (average of about $-28 \%$ ) and lower variability across the CMs.

To investigate the physical reasons underlying the changes in $Q$, we inspected the variation in the dominant runoff mechanisms. The partitioning of $Q$ at the RMB outlet into
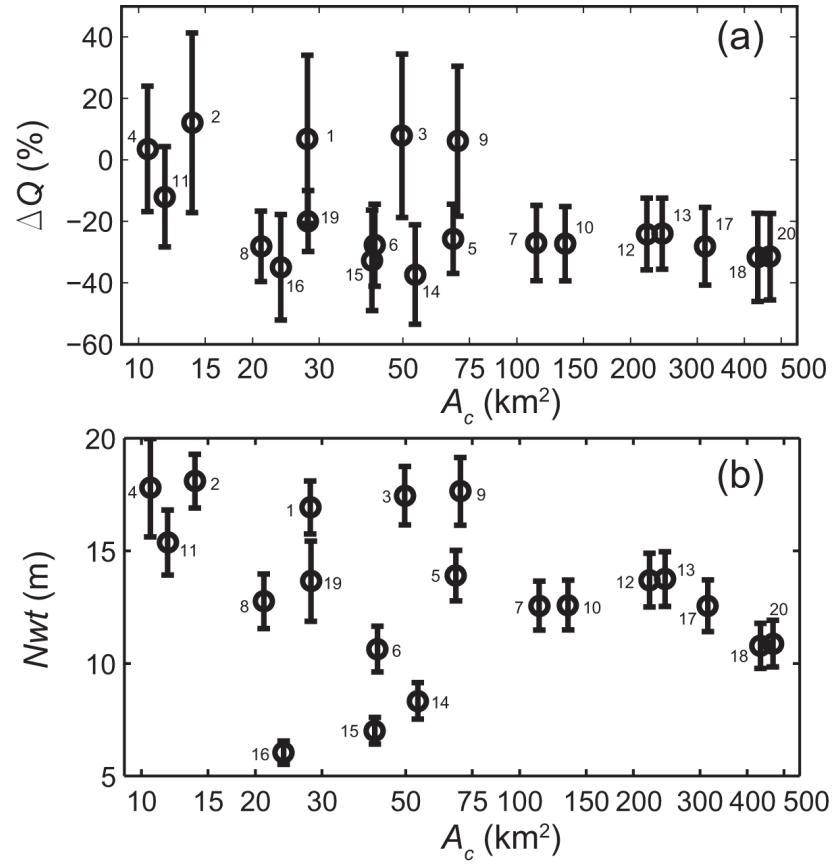

Figure 7. (a) Relation between the change in annual runoff, $\Delta Q$, and sub-basin contributing area, $A_{\mathrm{c}}$. (b) Relation between the mean level of the groundwater table, $N w t$, in the FUT period and $A_{\mathrm{c}}$. Bars represent mean \pm standard deviation across the CMs. The number of each sub-basin as reported in Fig. $2 b$ and Table 3 is also indicated. 
Table 3. Terrain, soil texture and land cover characteristics of the RMB sub-basins shown in Fig. 2b, including: contributing area $\left(A_{\mathrm{c}}\right)$, slope, and length of the main channel $(L)$; percentages of sandy loam-sandy clay loam (SL-SCL), clay loam-clay (CL-C), sandy loam-loam (SL-L); and percentages of agriculture (A), sparse vegetation (SV), and olives (O).

\begin{tabular}{|c|c|c|c|c|c|c|c|c|c|}
\hline \multirow[t]{2}{*}{ Sub-basin } & \multirow{2}{*}{$\begin{array}{r}A_{\mathrm{c}} \\
\left(\mathrm{km}^{2}\right)\end{array}$} & \multirow{2}{*}{$\begin{array}{r}\text { Slope } \\
(\%)\end{array}$} & \multirow{2}{*}{$\begin{array}{r}L \\
(\mathrm{~km})\end{array}$} & \multicolumn{3}{|c|}{ Main soil texture classes } & \multicolumn{3}{|c|}{ Main land cover classes } \\
\hline & & & & SL-SCL & CL-C & SL-L & A & SV & $\mathrm{O}$ \\
\hline 1 & 28.00 & 10.43 & 14.60 & 9.35 & 88.33 & 0.00 & 87.01 & 7.21 & 0.84 \\
\hline 2 & 14.82 & 9.03 & 7.15 & 5.05 & 89.98 & 0.00 & 71.81 & 3.48 & 17.34 \\
\hline 3 & 50.17 & 8.96 & 16.55 & 7.44 & 89.02 & 0.00 & 82.38 & 5.31 & 5.71 \\
\hline 4 & 10.78 & 5.56 & 8.09 & 17.40 & 77.35 & 0.00 & 90.83 & 0.00 & 4.44 \\
\hline 5 & 68.10 & 13.79 & 18.36 & 18.72 & 60.89 & 15.98 & 67.74 & 10.46 & 6.77 \\
\hline 6 & 42.67 & 22.93 & 16.51 & 3.37 & 26.98 & 69.05 & 31.33 & 39.13 & 5.82 \\
\hline 7 & 113.51 & 16.98 & 20.06 & 12.79 & 49.09 & 34.89 & 54.20 & 20.70 & 6.69 \\
\hline 8 & 20.95 & 16.59 & 13.55 & 0.00 & 58.55 & 31.52 & 30.34 & 25.43 & 16.77 \\
\hline 9 & 70.16 & 7.70 & 19.55 & 8.09 & 88.09 & 0.0 & 84.90 & 4.12 & 5.31 \\
\hline 10 & 135.01 & 16.89 & 21.07 & 10.85 & 50.38 & 34.38 & 50.68 & 21.43 & 8.16 \\
\hline 11 & 11.54 & 7.46 & 8.11 & 23.14 & 65.28 & 0.00 & 74.95 & 7.07 & 4.02 \\
\hline 12 & 221.99 & 13.71 & 27.40 & 11.46 & 60.65 & 21.49 & 60.65 & 16.19 & 7.67 \\
\hline 13 & 244.99 & 13.14 & 30.55 & 13.30 & 60.05 & 19.60 & 61.96 & 15.40 & 7.26 \\
\hline 14 & 8.18 & 19.05 & 22.43 & 21.42 & 3.28 & 42. & 25.05 & 47.24 & 8.86 \\
\hline 15 & 41.99 & 33.82 & 13.43 & 0.81 & 0.00 & 93.06 & 4.70 & 67.23 & 0.00 \\
\hline 16 & 23.96 & 34.58 & 10.76 & 5.57 & 0.09 & 94.18 & 2.44 & 74.56 & 4.35 \\
\hline 17 & 315.75 & 13.77 & 34.77 & 15.83 & 48.48 & 23.39 & 55.95 & 20.67 & 7.41 \\
\hline 18 & 436.41 & 16.67 & 25.45 & 19.25 & 35.63 & 34.06 & 45.39 & 28.16 & 8.54 \\
\hline 19 & 28.59 & 6.35 & 15.09 & 27.73 & 58.31 & 0.77 & 76.55 & 2.35 & 4.53 \\
\hline 20 outlet & 472.50 & 17.30 & 38.75 & 19.61 & 36.67 & 31.91 & 47.43 & 26.38 & 8.21 \\
\hline
\end{tabular}
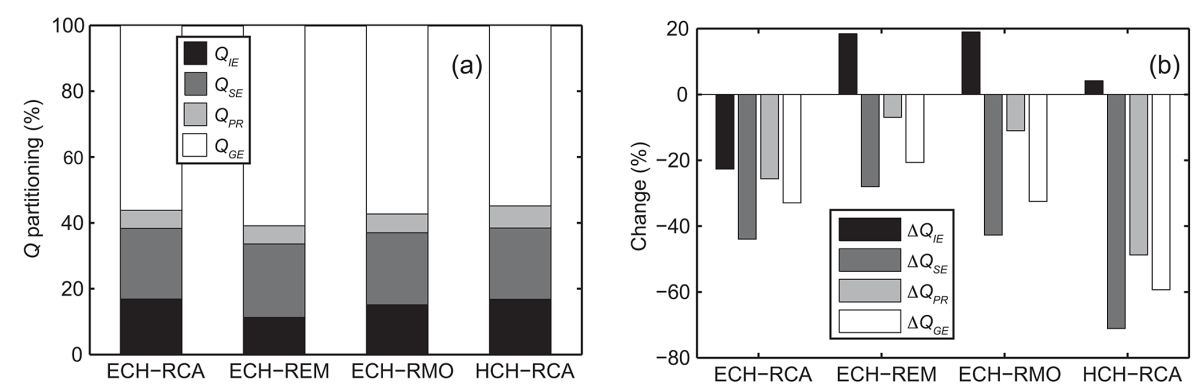

Figure 8. (a) Partitioning of $Q$ at the RMB outlet in the REF period among the four runoff generation mechanisms: infiltration excess ( $\left.Q_{\mathrm{IE}}\right)$, saturation excess $\left(Q_{\mathrm{SE}}\right)$, perched return flow $\left(Q_{\mathrm{PR}}\right)$, and groundwater exfiltration $\left(Q_{\mathrm{GE}}\right)$ runoff components. (b) $\Delta Q$ for the runoff mechanisms.

infiltration and saturation excess $\left(Q_{\mathrm{IE}}\right.$ and $\left.Q_{\mathrm{SE}}\right)$, groundwater exfiltration $\left(Q_{\mathrm{GE}}\right)$ and perched return flow $\left(Q_{\mathrm{PR}}\right)$ runoff is shown for each CM forcing in Fig. 8a for the REF period. The four combinations indicate the dominance of $Q_{\mathrm{GE}}$, followed by $Q_{\mathrm{SE}}, Q_{\mathrm{IE}}$ and $Q_{\mathrm{PR}}$. Figure $8 \mathrm{~b}$ presents the change in the amount of total $Q$ produced for each mechanism. All CMs predict a decrease in $Q_{\mathrm{SE}}, Q_{\mathrm{GE}}$, and $Q_{\mathrm{PR}}$, which are the components controlled by water availability in the soil, while $Q_{\mathrm{IE}}$ is expected to grow for all combinations except for ECH-RCA. This last runoff type occurs when the rainfall rate exceeds the infiltration capacity, suggesting that a variation of $Q_{\mathrm{IE}}$ in FUT may be due to a change in rainfall intensities during extreme events. To analyze this hypothe- sis, we derived the mean of the annual maxima of hourly $P$ over the 30-year records in FUT and REF periods for each $\mathrm{CM}$. Next, we computed the variation between these two average $P$ maxima from REF to FUT and we found a perfect correlation with the changes in $Q_{\mathrm{IE}}$.

Modifications in runoff generation mechanisms within the basin were evaluated by focusing on the sub-basins. We first point out that the mean annual change in $P$ is expected to be fairly constant in all sub-basins (not shown), suggesting that spatial differences may be mostly ascribed to surface and subsurface properties. In sub-basins 1-4 and 9, located in the northwest part of the RMB, $Q_{\mathrm{SE}}, Q_{\mathrm{GE}}$, and $Q_{\mathrm{PR}}$ decrease considerably more than in the rest of the watershed 
(mean changes of $-75,-70$ and $-50 \%$ ), while $Q_{\mathrm{IE}}$ slightly grows (mean change of $+10 \%$ ). For this set of sub-basins, we can conclude that (i) the small increase in $Q$ is due to a growth in $Q_{\mathrm{IE}}$, (ii) higher occurrence of $Q_{\mathrm{IE}}$ is due to more impermeable soils that make these sub-basins more sensitive to changes in rainfall intensity, and (iii) higher occurrence of $Q_{\mathrm{IE}}$ and the reduced buffer effect due to a deeper groundwater table (mean values shown in Fig. 7b for the FUT case) make their runoff response more uncertain for the CMs. For the other set of sub-basins (i) total $Q$ decreases due to a general reduction of all components, and (ii) the uncertainty in runoff response is relatively lower, especially for increasing $A_{\mathrm{c}}$.

\subsection{Changes in hydrologic extremes}

Changes in hydrologic extremes are investigated in terms of (i) low flow persistence, which can be assumed as a proxy of drought periods, and (ii) occurrence of high flows. To analyze the impacts on the first type of extremes, we computed flow duration curves (FDCs) for $Q$ at the outlet. Figure 9 clearly shows a downward shift in the FDCs over most exceedances, consistent with the predicted reduction of total $Q$ in the FUT period. To identify the low flow conditions, we first calculated a threshold discharge, $Q_{\mathrm{LF}}$, as the streamflow corresponding to the $70 \%$ percentage of exceedance for the REF period (circle in Fig. 9). Low flow conditions were then defined as the periods during which $Q<Q_{\mathrm{LF}}$. Figure 10a shows that the monthly mean number of low flow days is expected to increase in FUT for about 5 days for each month, implying more frequent dry conditions. The annual average of the maximum consecutive length of low flow days is reported in Fig. 10b. In current conditions, all combinations robustly simulate a value of about 50 days occurring during the summer months. In the future, the length is expected to increase from 19 to 52 days on average, depending on the $\mathrm{CM}$, thus extending the low flow conditions to spring and/or fall. This result confirms and further details previous findings on future drought in the Mediterranean region (e.g., Beniston et al., 2007).

Concerning the second type of extremes, we used the time series of $Q$ at the outlet and 19 internal sub-basins. For the REF and FUT periods, (i) the index flood was obtained for each sub-basin by averaging the corresponding 30 yearly $Q$ maxima, and (ii) the ratio between the index flood and the corresponding $A_{\mathrm{c}}$ was computed. This ratio, labeled as $\mu_{\mathrm{c}}$, was found to remain fairly constant as a function of $A_{\mathrm{c}}$ and, thus, was used to remove the effect of their size. We then computed the changes of $\Delta \mu_{\mathrm{c}}$ from REF to FUT and explored their relation with terrain attributes and soil texture. Results of this analysis are summarized in Fig. 11 where $\Delta \mu_{\mathrm{c}}$ is plotted against the mean sub-basin slope for each CM. Predictions under three combinations (ECH-REM, ECH-RMO and $\mathrm{HCH}-\mathrm{RCA}$ ) indicate that the magnitude of the mean annual $Q$ maxima will increase in the FUT period as the basin

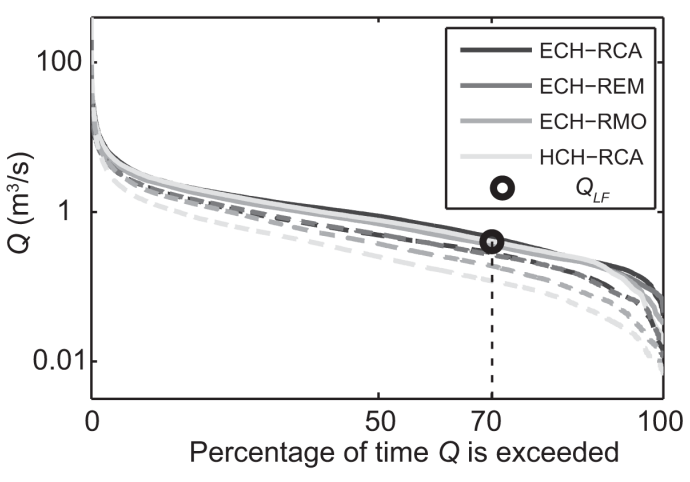

Figure 9. FDCs computed from the discharge at the RMB outlet. Continuous (dashed) lines are used for REF (FUT). Circle shows the threshold discharge, $Q_{\mathrm{LF}}$, used to identify low flow conditions.

slope decreases and when soils are dominated by clay and loam (Fig. 11b-d). For the ECH-RCA case, a negative $\Delta \mu_{\mathrm{c}}$ was instead systematically detected for all sub-basins, without any clear link to soil type and basin slope (Fig. 11a). This behavior is again explained with changes in the rainfall intensities of extreme events: for the first three CMs, the mean of the annual maxima of hourly $P$ is expected to increase in the future, while a reduction is predicted for the latter $\mathrm{CM}$. As previously discussed, this is reflected in similar changes in $Q_{\mathrm{IE}}$, which is the dominant runoff mechanism during floods. It is worth noting that the highest positive $\Delta \mu_{\mathrm{c}}$ values in Fig. 11b-d are found for sub-basins $1-4$ and 9, characterized by lower slope and dominated by more impermeable soils (clay and loam), where a relatively higher increase in $Q_{\mathrm{IE}}$ is expected.

\subsection{Changes in evapotranspiration and soil water content}

Figure 12a shows time series of the mean and standard deviation of monthly average $\mathrm{ET}_{0}$ and $\mathrm{ET}_{\mathrm{a}}$ in the REF and FUT periods. As expected, projections of higher $T$ in the future leads to increasing $\mathrm{ET}_{0}$. In contrast, a reduced $\mathrm{ET}_{\mathrm{a}}$ is simulated for most of the year, except for January, May and November. This is mainly due to the reduction of soil water content (SWC) in the root zone in the FUT period, which is related to the decreases of $P$. This is clearly shown in Fig. 12b, where we can observe a marked reduction throughout the year of SWC and a negative change of $\mathrm{ET}_{\mathrm{a}}$, despite a systematic positive variation of $\mathrm{ET}_{0}$. These findings are mostly in accordance with Senatore et al. (2011), who found decreasing $\mathrm{ET}_{\mathrm{a}}$ in winter and diminishing SWC across the year.

The feedbacks among changes in $\mathrm{ET}_{\mathrm{a}}$ and $\mathrm{SWC}$, and their relation with meteorological forcing ( $P$ and $T$, and consequently $\mathrm{ET}_{0}$ ) and basin characteristics (soil texture and topography) were investigated using the spatial model outputs. As an example, Figs. 13 and 14 show maps of $\Delta P, \Delta \mathrm{SWC}$, 

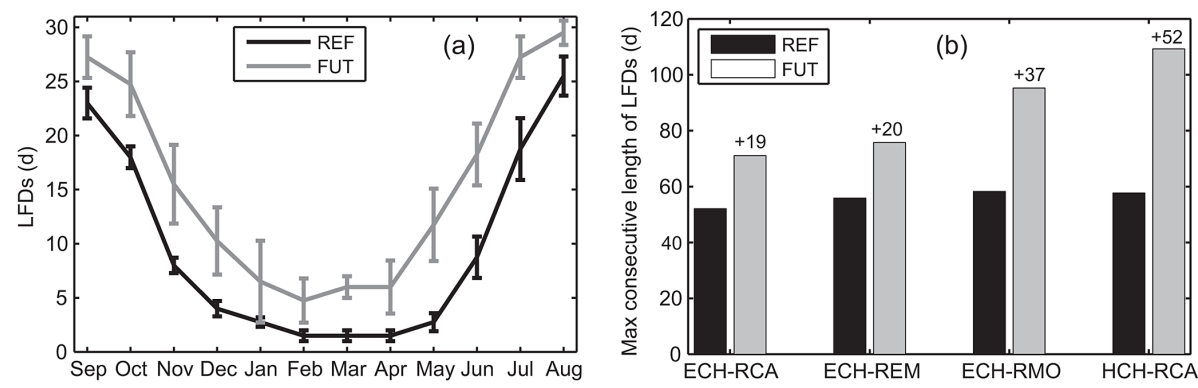

Figure 10. (a) Mean monthly number of low flow days (LFDs) in REF (black) and FUT (gray). Bars are mean \pm standard deviation across the CMs. (b) Mean annual maximum consecutive length of LFDs in REF (black) and FUT (gray) periods.
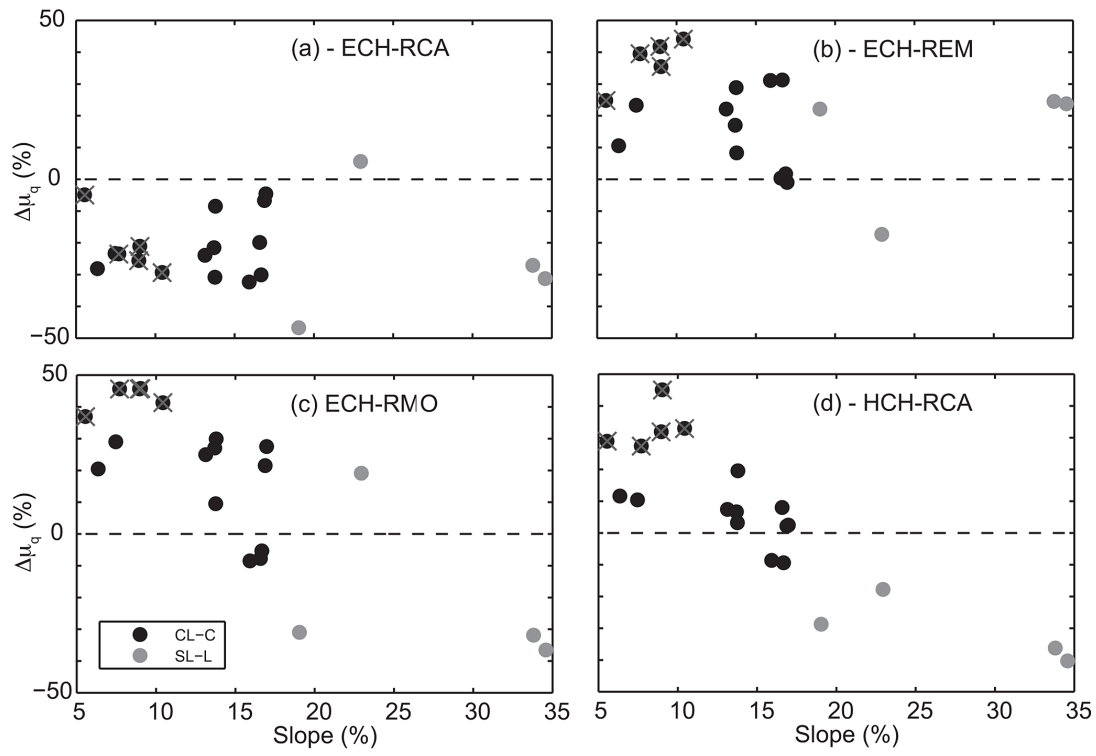

Figure 11. Relation between the change in the mean of the annual maximum $Q, \Delta \mu_{q}$, and the corresponding mean slope. Black (gray) circles indicate sub-basins dominated by the clay loam-clay (sandy loam-loam) class; a cross is used to indicate sub-basins 1-4 and 9. Each panel refers to results obtained for each CM.

$\Delta \mathrm{ET}_{0}$ and $\Delta \mathrm{ET}_{\mathrm{a}}$ in winter (December-February) and spring (March-May) seasons, which are characterized by the smallest and largest $\Delta P$ and $\Delta \mathrm{ET}_{0}$ in the $\mathrm{ECH}-\mathrm{RCA}$ forcing. The behavior found in the other seasons is similar to the dynamics in spring, while results derived for other climate model combinations are not significantly different.

In winter, the basin-averaged changes in $P$ are small $(\Delta P=-1.92 \%)$, limiting SWC decreases and leaving enough soil water for evapotranspiration. A higher $\mathrm{ET}_{0} \quad\left(\Delta \mathrm{ET}_{0}=+3.30 \%\right)$ allows $\mathrm{ET}_{\mathrm{a}}$ to rise slightly $\left(\Delta \mathrm{ET}_{\mathrm{a}}=+0.14 \%\right)$. The combined effect of decreasing water input from $P$ and higher $\mathrm{ET}_{\mathrm{a}}$ causes a basin-averaged reduction of SWC of $-3.66 \%$. The pattern of $\triangle$ SWC (Fig. 13b) is mostly influenced by soil texture and, to a less extent, by $\Delta P$ (Fig. 13a) and $\Delta \mathrm{ET}_{0}$ (Fig. 13c). Lower $\Delta \mathrm{SWC}$ (from -2.0 to $+0.9 \%)$ are found in the sandy loam-loam class where $\Delta P$ is slightly negative to positive (indicated with $L$ in Fig. 13b). In these regions, soil water is available to be ex- tracted at a higher rate $\left(\Delta \mathrm{ET}_{0}\right.$ varies from +3.1 to $\left.+4.0 \%\right)$, thus causing $\mathrm{ET}_{\mathrm{a}}$ to grow from +3 to $+8 \%$. SWC is expected to decrease more significantly (from -3 to $-20 \%$ ) in areas of clay loam-clay and sandy loam-sandy clay loam (labeled $H$ in Fig. 13b), where $P$ decreases by up to $-7 \%$ and $\mathrm{ET}_{0}$ does not vary substantially $(+2 \%)$. Note that this area mostly contains sub-basins 1-4 and 9, which experience the highest reductions of $Q_{\mathrm{SE}}, Q_{\mathrm{GE}}$ and $Q_{\mathrm{PR}}$. As expected, the spatial pattern of $\triangle \mathrm{ET}_{\mathrm{a}}$ is highly correlated with $\triangle \mathrm{SWC}$ (correlation coefficient of 0.80 ), with a minor dependence on $\Delta \mathrm{ET}_{0}$, although its signature is also apparent.

In spring, $P$ is predicted in FUT to be noticeably lower (basin-averaged $\Delta P=-28.37 \%$ ) and $\mathrm{ET}_{0}$ higher $\left(\Delta \mathrm{ET}_{0}=+5.51 \%\right)$. As a consequence, the decrease in SWC is more significant ( $\triangle \mathrm{SWC}=-7.13 \%)$ and the water available for evapotranspiration is limited, causing $\mathrm{ET}_{\mathrm{a}}$ to diminish $\left(\Delta \mathrm{ET}_{\mathrm{a}}=-2.12 \%\right)$, despite the positive trend of $\mathrm{ET}_{0}$. In most of the basin, $\triangle \mathrm{SWC}$ ranges from -6 to $-7 \%$ ( $L$ 

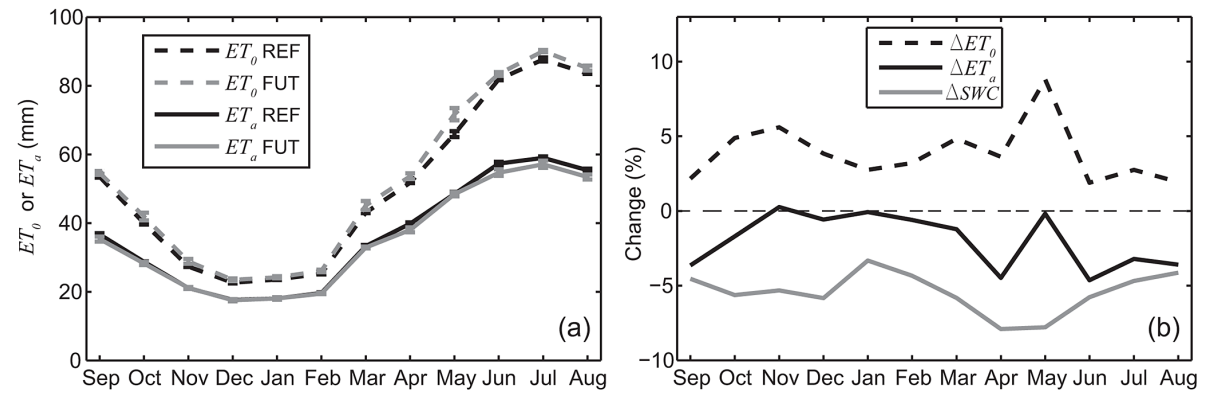

Figure 12. (a) Mean monthly $\mathrm{ET}_{0}$ (dashed lines) and $\mathrm{ET}_{\mathrm{a}}$ (continuous lines) plotted as mean \pm standard deviation of the four $\mathrm{CMs}$ in $\mathrm{REF}$ (black) and FUT (gray); (b) mean across the CMs of the relative changes of $\mathrm{ET}_{0}, \mathrm{ET}_{\mathrm{a}}$, and $\mathrm{SWC}$.

(a) $\Delta P$

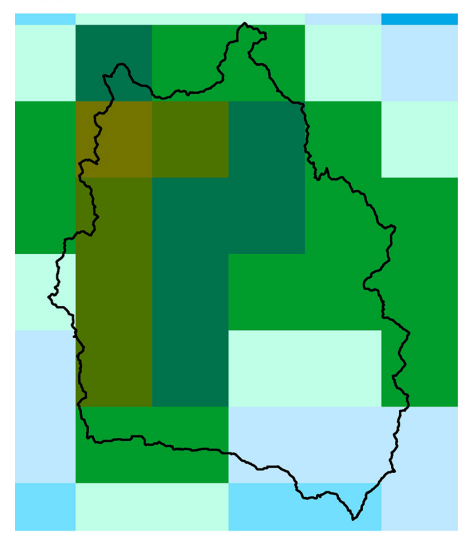

(c) $\Delta E T_{0}$
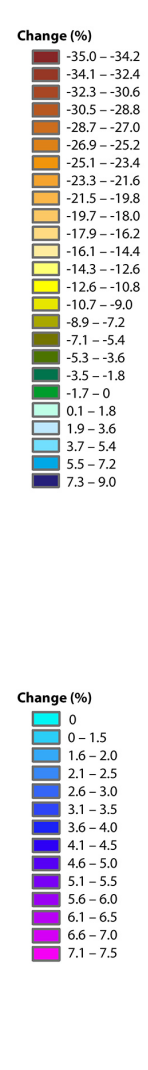

(b) $\triangle S W C$

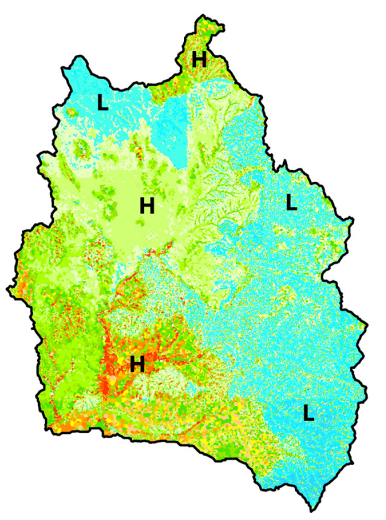

(d) $\Delta E T_{a}$

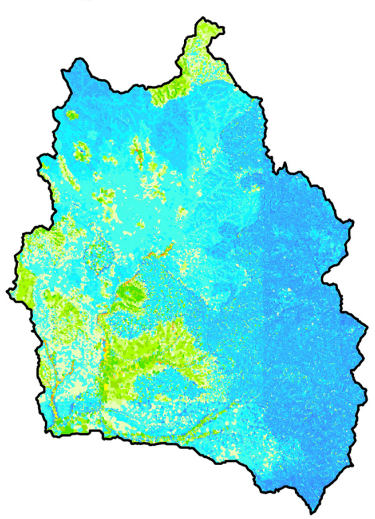

Winter

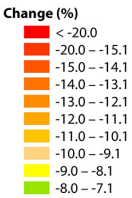

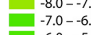

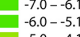

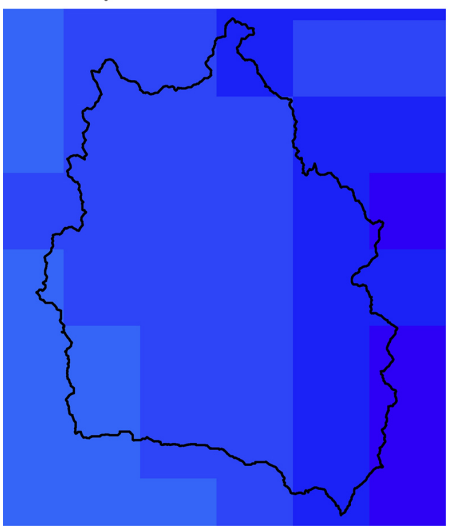

Figure 13. Changes between REF and FUT periods averaged over the winter season (December-February) for (a) $P$, (b) $\mathrm{SWC}_{\text {, }}(\mathbf{c}) \mathrm{ET}_{0}$, and (d) $\mathrm{ET}_{\mathrm{a}}$ under the ECH-RCA combination. In (b), areas where the variables are characterized by positive or lower negative changes are indicated with $L$, while regions with higher negative changes are indicated with $H$.

areas in Fig. 14b), likely due to the relatively low spatial variability of $\Delta P$ (Fig. 14a). Higher drops in SWC (up to $-20 \%$ ) occur in the areas dominated by sandy loam-sandy clay loam where $P$ decreases more ( $H$ areas in Fig. 14b). Topography also plays a role, as reduced drops of SWC appear in areas of flow convergence close to streams. $\Delta \mathrm{ET}_{\mathrm{a}}$ (Fig. 14d) is still well correlated to $\triangle \mathrm{SWC}$ (correlation coefficient of 0.75) and also affected by $\Delta \mathrm{ET}_{0}$ (Fig. 14c). $\mathrm{ET}_{\mathrm{a}}$ remains essentially constant in the areas labeled with $L$ in Fig. 14d, characterized by lower changes in SWC and relatively higher $\Delta \mathrm{ET}_{0} . \mathrm{ET}_{\mathrm{a}}$ decreases instead significantly (up to $-12 \% ; H$ areas) in the regions where the drop of SWC is the largest and changes in $\mathrm{ET}_{0}$ are modest. The effect of topography can be better appreciated in the map of $\Delta \mathrm{ET}_{\mathrm{a}}$ : higher values $(+10 \%)$ are simulated in the areas close to the stream network with higher availability of water. 
(a) $\Delta P$

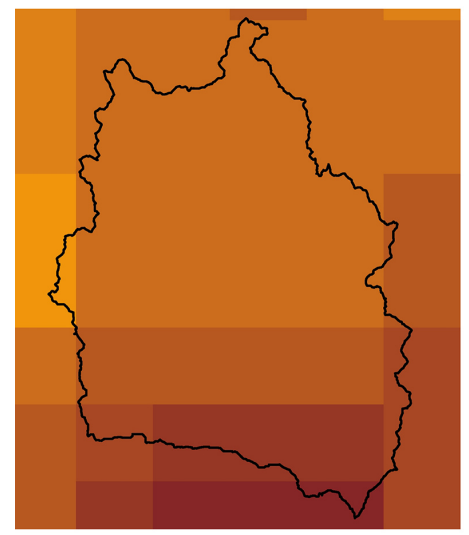

(c) $\Delta E T_{0}$

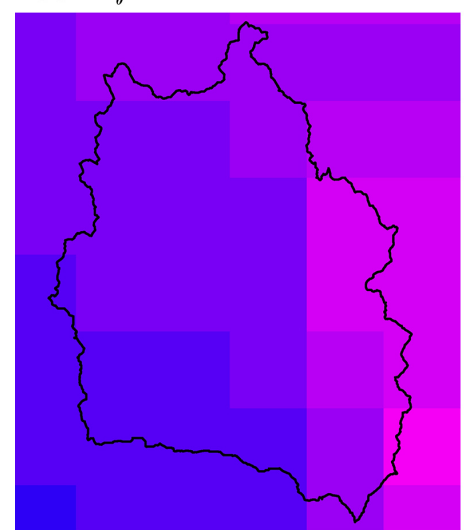

(b) $\triangle S W C$
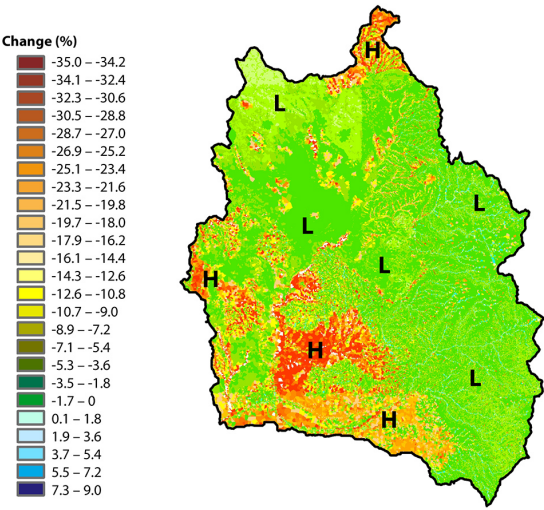

(d) $\triangle E T$

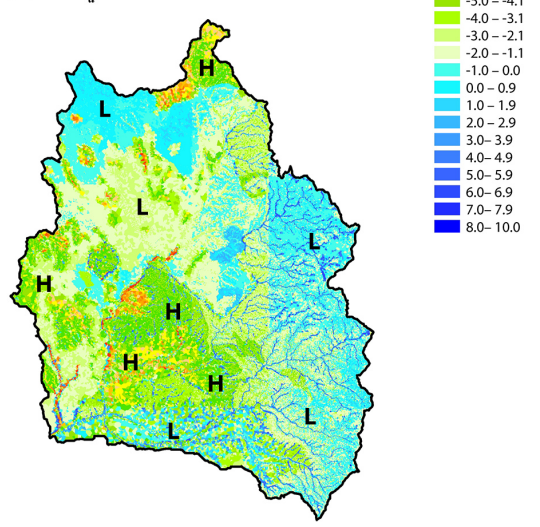

\section{Spring}
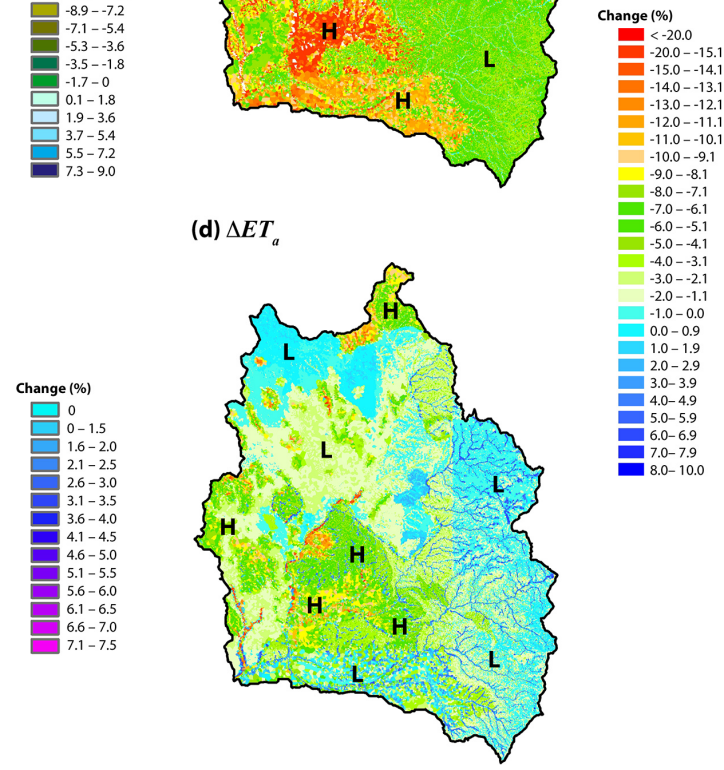

Figure 14. Same as Fig. 13, but for the spring season.

This analysis reveals that, despite higher $\mathrm{ET}_{0}$, the RMB will experience in the future a decrease in $\mathrm{ET}_{\mathrm{a}}$ in most areas and times of the year, due to the lack of soil water caused by lower rainfall. The only season with a different behavior is winter, where $P$ is expected to decrease to a lesser extent or slightly increase, thus limiting the reduction in SWC and leading in certain areas to higher $\mathrm{ET}_{\mathrm{a}}$. The patterns of SWC and $\mathrm{ET}_{\mathrm{a}}$ are mainly controlled by soil texture and the interaction of $P$ and $\mathrm{ET}_{0}$. Terrain plays also a role when reductions of $P$ are more significant.

\subsection{Changes in groundwater}

A last analysis was devoted to evaluate the impact of climate change on groundwater. For this aim, we computed the difference between the basin-averaged groundwater level at the end of the 30-year simulation in FUT and REF periods. For all sets of climate forcing, we found a drop of the water table ranging from 1.0 to $4.6 \mathrm{~m}$, constant across the year. The amount of the drop simulated for each CM is linked to the corresponding diminution in $P$ input (lowest for ECH-REM and highest for HCH-RCA). In fact, a decreasing rainfall input leads to a decrease of the soil water content in the unsatu- rated zone and reduces the recharge to the aquifer. This result is confirmed by the diminishing occurrence of $Q_{\mathrm{GE}}$ (Fig. 8b).

\section{Conclusions}

In this study, we quantified the impacts of climate change on water resources and hydrologic extremes in an agricultural Mediterranean basin of $472.5 \mathrm{~km}^{2}$ located in Sardinia, Italy. For this aim, the process-based tRIBS model was used to capture the large variety of the hydrologic conditions occurring in Mediterranean areas. The forcings in reference (1971-2000) and future (2041-2070) periods were provided by outputs from four combinations of GCMs and RCMs, bias-corrected and downscaled in space and time through statistical tools. The adoption of disaggregation tools was crucial to create high-resolution $(5 \mathrm{~km}, 1 \mathrm{~h})$ inputs required to apply this type of hydrologic model. Outputs of the hydrologic simulations were then compared in the reference and future periods to quantify the changes in several variables. The main results of this study are summarized below.

At annual scale, all CMs predict decreasing $P$ (mean of $-12.70 \%$ ) and increasing $T$ (mean $+2.18^{\circ} \mathrm{C}$ ), leading to a significant diminution of $Q(-32.55 \%)$ at the basin outlet. 
The changes in future climate will mostly lead to a reduction of those runoff generation mechanisms that depend on water available in the soil, namely $Q_{\mathrm{SE}}, Q_{\mathrm{PR}}$ and $Q_{\mathrm{GE}}$. A higher degree of uncertainty across the climate model combinations was found while predicting the variation in $Q_{\mathrm{IE}}$, which depends on the combined effect of rainfall intensities and soil hydraulic properties.

Changes in annual $Q$ were also investigated at distributed locations, finding two sets of sub-basins with different behavior. In the northwest region, characterized by flatter terrain and clay-loam soils, the mean $Q$ is expected to increase somewhat in the future. Specifically, a small growth in $Q_{\text {IE }}$ is anticipated, while $Q_{\mathrm{SE}}, Q_{\mathrm{PR}}$ and $Q_{\mathrm{GE}}$ will have the largest reductions over the basin. Hydrologic responses in this area under different $\mathrm{CMs}$ are affected by higher uncertainty, due to the higher occurrence of the faster runoff component ( $Q_{\mathrm{IE}}$ ) and the lower contribution of slower subsurface components ( $Q_{\mathrm{PR}}$ and $Q_{\mathrm{GE}}$ ) that tend to attenuate the variability of the climate forcing. In contrast, for other sub-basins in the RMB, $Q$ is anticipated to diminish with relatively low uncertainty across the four CMs, due to a decreasing contribution of all runoff components.

At basin scale, the combined effect of lower $P$ and higher $T$ leads to increasing $\mathrm{ET}_{0}$ and decreasing SWC throughout the year, and diminishing $\mathrm{ET}_{\mathrm{a}}$ over all months except for winter. The spatiotemporal analysis of the interactions between $\mathrm{SWC}$ and $\mathrm{ET}_{\mathrm{a}}$ reveals that (i) in most areas and times of the year, negative changes of $P$ lead to a reduction in $\mathrm{ET}_{\mathrm{a}}$, because there is not enough soil water to sustain the higher evaporative demand; (ii) in winter, some areas experience a modest decrease or a slight rise of $P$, leading to local growth in $\mathrm{ET}_{\mathrm{a}}$; (iii) soil texture controls the amount of the variations in SWC, with higher drops in the sandy loamsandy clay loam class; and (iv) topography also plays a role with positive changes in SWC and $\mathrm{ET}_{\mathrm{a}}$ found in areas of flow convergence near the stream network.

To our knowledge, this is the first climate change study conducted in Sardinia at the watershed scale. Results suggest that the basin's hydrologic regime will be significantly impacted by variations in future climate. The diminution in annual $Q$ at the outlet implies that (i) the inflow at the reservoir located in proximity of the outlet will be reduced, and (ii) more frequent and longer low flow conditions, which are an indication of hydrological drought, are expected. In addition, agricultural areas are anticipated to experience the largest drop in SWC in the root zone (mean of $-6 \%$ ) among all land cover classes. This finding, in conjunction with the decreasing $P$, may have important impacts on the crops (especially the rain-fed areas) that are currently grown in the basin. As a result, the implications of this study are useful to support the selection of adaptive strategies for water and crop management and planning under climate change, as well as to quantify the social and economic vulnerability of the region.
Finally, we point out that, as any climate change study, the methodology adopted here is affected by uncertainties and limitations. The climate model uncertainty was addressed by selecting the best-performing four combinations of global and regional climate models in reproducing precipitation and temperature in the study basin. Due to the lack of observations (a common problem in this region), the hydrologic model was calibrated and validated only with 3 years of data. To address this issue and identify robust model parameters, we selected the calibration and validation periods characterized by markedly different hydrologic conditions. A single set of techniques, commonly used in climate change studies, was applied to correct the bias of CM outputs. In addition, statistical downscaling tools were adopted to simulate the small-scale variability of precipitation and temperature, with calibration relations assumed stationary from current to future climate. While a process-based model like tRIBS has the potential to capture the basin response at high resolution and allows conducting distributed analyses, current computational constraints have limited the possibility to deal with other sources of uncertainty, including testing the effect of different types of bias correction methods (e.g., Tramblay et al., 2013). Finally, we plan to devote future work to address the uncertainty of hydrologic modeling, by comparing outputs from different models applied in the RMB by several research groups in the context of the CLIMB project.

Acknowledgements. This study was developed as part of the project CLIMB (http://www.climb-fp7.eu) funded by the European Commission's 7th Framework Program. The authors also thank financial support by the Sardinian Region L. R. 7/2007, funding call 2008. They acknowledge the ENSEMBLES project, funded by the EU-FP6 through contract GOCE-CT-2003-505539, and the data providers in the ECA \& D project for making RCM outputs and the E-OBS data set available. Two anonymous reviewers are thanked for their comments that helped to improve the quality of the manuscript.

Edited by: E. Morin

\section{References}

Abbaspour, K. C., Faramarzi, M., Ghasemi, S. S., and Yang, H.: Assessing the impact of climate change on water resources in Iran, Water Resour. Res., 45, W10434, doi:10.1029/2008WR007615, 2009.

Badas, M. G., Deidda, R., and Piga, E.: Modulation of homogeneous space-time rainfall cascades to account for orographic influences, Nat. Hazards Earth Syst. Sci., 6, 427-437, doi:10.5194/nhess-6-427-2006, 2006.

Bardossy, A. and Pegram, G.: Downscaling precipitation using regional climate models and circulations patterns toward hydrology, Water Resour. Res., 47, W04505, doi:10.1029/2010WR009689, 2011. 
Beniston, M., Stephenson, D. B., Christensen, O. B., Ferro, C. A. T., Frei, C., Goyette, S., Halsnaes, K., Holt, T., Jylhä, K., Koffi, B., Palutikof, J., Schöll, R., Semmler, T., and Woth, K.: Future extreme events in European climate: an exploration of regional climate model projections, Climatic Change, 81, 71-95, doi:10.1007/s10584-006-9226-z, 2007.

Beven, K.: Runoff generation in semi-arid areas, in: Dryland Rivers, edited by: Bull, L. J., and Kirkby, M. J., J. Wiley \& Sons, West Sussex, England, 57-105, 2002.

Borga, M., Boscolo, P., Zanon, F., and Sangati, M.: Hydrometeorological Analysis of the 29 August 2003 Flash Flood in the Eastern Italian Alps, J. Hydrometeorol., 8, 1049-1067, 2007.

Camici, S., Brocca, L., Melone, F., and Moramarco, T.: Impact of climate change on flood frequency using different climate models and downscaling approaches, J. Hydrol. Eng., 19, 04014002 , doi:10.1061/(ASCE)HE.1943-5584.0000959, 2014.

Cayan, D. R., Dasa, T., Piercea, D. W., Barnetta, T. P., Tyreea, M., and Gershunova, A.: Future dryness in the southwest US and the hydrology of the early 21 st century drought, P. Natl. Acad. Sci. USA, 107, 21271-21276, doi:10.1073/pnas.0912391107, 2010.

Chessa, P. A., Cesari, D., and Delitala, A. M. S.: Mesoscale precipitation and temperature regimes in Sardinia (Italy) and their related synoptic circulation, Theor. Appl. Climatol., 63, 195-221, 1999.

Christensen, J. H., Boberg, F., Christensen, O. B., and LucasPicher, P.: On the need for bias correction of regional climate change projections of temperature and precipitation, Geophys. Res. Lett., 35, 1-6, 2008.

Deidda, R.: Multifractal analysis and simulation of rainfall fields in space, Phys. Chem. Earth, 24, 73-78, 1999.

Deidda, R.: Rainfall downscaling in a space-time multifractal framework, Water Resour. Res., 36, 1779-1784, 2000.

Deidda, R., Marrocu, M., Caroletti, G., Pusceddu, G., Langousis, A., Lucarini, V., Puliga, M., and Speranza, A.: Regional climate models' performance in representing precipitation and temperature over selected Mediterranean areas, Hydrol. Earth Syst. Sci., 17, 5041-5059, doi:10.5194/hess-17-5041-2013, 2013.

Delrieu, G., Nicol, J., Yates, E., Kirstetter, P.-E., Creutin, J.-D., Anquetin, S., Obled, C., and Saulnier, G.-M.: The catastrophic flash-flood event of 8-9 September 2002 in the Gard region, France: a first case study for the Cévennes-Vivarais Mediterranean hydrometeorological observatory, J. Hydrometeorol., 6, 34-52, 2005.

Falloon, P. and Betts, R.: Climate impacts on European agriculture and water management in the context of adaptation and mitigation-The importance of an integrated approach, Sci. Total Environ., 408, 5667-5687, doi:10.1016/j.scitotenv.2009.05.002, 2010.

Frei, C., Schöll, R., Fukutome, S., Schmidli, J., and Vidale, P. L.: Future change of precipitation extremes in Europe: intercomparison of scenarios from regional climate models, J. Geophys. Res., 111, D06105, doi:10.1029/2005JD005965, 2006.

Gallart, F., Llorens, P., Latron, J., and Regüés, D.: Hydrological processes and their seasonal controls in a small Mediterranean mountain catchment in the Pyrenees, Hydrol. Earth Syst. Sci., 6, 527-537, doi:10.5194/hess-6-527-2002, 2002.

Giorgi, F.: Climate change hot-spots, Geophys. Res. Lett., 33, L08707, doi:10.1029/2006GL025734, 2006.
Giorgi, F. and Lionello, P.: Climate change projections for the Mediterranean region, Global Planet. Change, 63, 90-104, 2008.

Hasson, S., Lucarini, V., and Pascale, S.: Hydrological cycle over South and Southeast Asian river basins as simulated by PCMDI/CMIP3 experiments, Earth Syst. Dynam., 4, 199-217, doi:10.5194/esd-4-199-2013, 2013.

Hasson, S., Lucarini, V., Pascale, S., and Böhner, J.: Seasonality of the hydrological cycle in major South and Southeast Asian river basins as simulated by PCMDI/CMIP3 experiments, Earth Syst. Dynam., 5, 67-87, doi:10.5194/esd-5-67-2014, 2014.

Haylock, M. R., Hofstra, N., Klein Tank, A. M. G., Klok, E. J., Jones, P. D., and New, M.: A European daily high-resolution gridded dataset of surface temperature and precipitation, J. Geophys. Res.-Atmos., 113, D20119, doi:10.1029/2008JD010201, 2008.

Hoerling, M., Eischeid, J., Perlwitz, J., Quan, X., Zhang, T., and Pegion, P.: On the Increased Frequency of Mediterranean Drought, J. Climate, 25, 2146-2161, doi:10.1175/JCLI-D-1100296.1, 2012.

IPCC - Intergovernmental Panel on Climate Change: Climate change 2007: impacts, adaptation and vulnerability, in: Contribution of Working Group II to the Fourth Assessment Report of the Intergovernmental Panel on Climate Change, Cambridge University Press, Cambridge, UK, 872-878, 2007.

Ivanov, V. Y., Vivoni, E. R., Bras, R. L., and Entekhabi, D.: Catchment hydrologic response with a fully-distributed triangulated irregular network model, Water Resour. Res., 40, 1-23, doi:10.1029/2004WR003218, 2004a.

Ivanov, V. Y., Vivoni, E. R., Bras, R. L., and Entekhabi, D.: Preserving high-resolution surface and rainfall data in operational-scale basin hydrology: A fully-distributed physically-based approach, J. Hydrol., 298, 80-111, doi:10.1016/j.jhydrol.2004.03.041, 2004b.

Liston, G. E. and Elder, K.: A Meteorological Distribution System for High-Resolution Terrestrial Modeling (Micro Met), J. Hydrometeorol., 7, 217-234, 2006.

Liuzzo, L., Noto, L. V., Vivoni, E. R., and La Loggia, G.: Basin-scale water resources assessment in Oklahoma under synthetic climate change scenarios using a fully distributed hydrological model, J. Hydrol. Eng., 15, 107-122, doi:10.1061/(ASCE)HE.1943-5584.0000166, 2010.

Lucarini, V.: Validation of climate models, in: Encyclopaedia of Global Warming and Climate Change, edited by: Philander, G., SAGE, Thousand Oaks, USA, 1053-1057, 2008.

Lucarini, V., Danihlik, R., Kriegerova, I., and Speranza, A.: Does the Danube exist? Versions of reality given by various regional climate models and climatological data sets, J. Geophys. Res., 112, D13103, doi:10.1029/2006JD008360, 2007.

Lucarini, V., Danihlik, R., Kriegerova, I., and Speranza, A.: Hydrological cycle in the Danube basin in present-day and XXII century simulations by IPCCAR4 global climate models, J. Geophys. Res., 113, D09107, doi:10.1029/2007JD009167, 2008.

Ludwig, R., Soddu, A., Duttmann, R., Baghdadi, N., Benabdallah, S., Deidda, R., Marrocu, M., Strunz, G., Wendland, F., Engin, G., Paniconi, C., Prettenthaler, F., Lajeunesse, I., Afifi, S., Cassiani, G., Bellin, A., Mabrouk, B., Bach, H., and Ammerl, T.: Climateinduced changes on the hydrology of Mediterranean basins - A research concept to reduce uncertainty and quantify risk, Fresen. Environ. Bull., 19, 2379-2384, 2010. 
Mahfouf, J. F. and Noilhan, J.: Comparative study of various formulations from bare soil using in situ data, J. Appl. Meteorol., 30, 1354-1365, 1991.

Mahmood, T. H. and Vivoni, E. R.: Forest ecohydrological response to bimodal precipitation during contrasting winter to summer transitions, Ecohydrology, 7, 998-1013, doi:10.1002/eco.1424, 2014.

Maraun, F., Wetterhall, A. M., Ireson, R. E., Chandler, E. J., Kendon, M., Widmann, S., Brienen, H. W., Rust, T., Sauter, M., Themeß1,V. K. C., Venema, K. P., Chun, C. M., Goodess, R. G., Jones, C., Onof, M., Vrac, I., and Thiele-Eich, I.: Precipitation downscaling under climate change. Recent developments to bridge the gap between dynamical models and the end user, Rev. Geophys., 48, RG3003, doi:10.1029/2009RG000314, 2010.

Mariotti, A.: Recent changes in the Mediterranean water cycle: A pathway toward long-term regional hydroclimatic change?, J. Climate, 23, 1513-1525, 2010.

Mariotti, A., Zeng, N., Yoon, J.-H., Artale, V., Navarra, A., Alpert, P., and Li, L. Z. X.: Mediterranean water cycle changes: Transition to drier 21st century conditions in observations and CMIP3 simulations, Environ. Res. Lett., 3, 044001, doi:10.1088/17489326/3/4/044001, 2008.

Mascaro, G., Vivoni, E. R., and Deidda, R.: Implications of ensemble quantitative precipitation forecast errors on distributed streamflow forecasting, J. Hydrometeorol., 11, 69-86, doi:10.1175/2009JHM1144.1, 2010.

Mascaro, G., Piras, M., Deidda, R., and Vivoni, E. R.: Distributed hydrologic modeling of a sparsely monitored basin in Sardinia, Italy, through hydrometeorological downscaling, Hydrol. Earth Syst. Sci., 17, 4143-4158, doi:10.5194/hess-17-41432013, 2013a.

Mascaro, G., Deidda, R., and Hellies, M.: On the nature of rainfall intermittency as revealed by different metrics and sampling approaches, Hydrol. Earth Syst. Sci., 17, 355-369, doi:10.5194/hess-17-355-2013, 2013b.

Maurer, E. P. and Hidalgo, H. G.: Utility of daily vs. monthly large-scale climate data: an intercomparison of two statistical downscaling methods, Hydrol. Earth Syst. Sci., 12, 551-563, doi:10.5194/hess-12-551-2008, 2008.

Montenegro, S. and Ragab, R.: Impact of possible climate and land use changes in the semi arid regions: a case study from North Eastern Brazil, J. Hydrol., 434-435, 55-68, doi:10.1016/j.jhydrol.2012.02.036, 2012.

Moreno, H. A., Vivoni, E. R., and Gochis, D. J.: Limits to flood forecasting in the Colorado Front Range for two summer convection periods using radar nowcasting and a distributed hydrologic model, J. Hydrometeorol., 14, 1075-1097, 2013.

Moussa, R., Chahinian, N., and Bocquillon, C.: Distributed hydrological modeling of a Mediterranean mountainous catchment model construction and multi-site validation, J. Hydrol., 337, 3551, doi:10.1016/j.jhydrol.2007.01.028, 2007.

Nakićeović, N., Alcamo, J., Davis, G., de Vries, H. J. M., Fenhann, J., Gaffin, S., Gregory, K., Grubler, A., Jung, T. Y., Kram, T., La Rovere, E. L., Michaelis, L., Mori, S., Morita, T., Papper, W., Pitcher, H., Price, L., Riahi, K., Roehrl, A., Rogner, H.-H., Sankovski, A., Schlesinger, M., Shukla, P., Smith, S., Swart, R., van Rooijen, S., Victor, N., and Dadi, Z.: Emissions Scenarios, A Special Report of Working Group III of the Intergovernmen- tal Panel on Climate Change, Cambridge University Press, Cambridge, 2000.

Olesen, J. E. and Bindi, M.: Consequences of climate change for European agricultural productivity, land use and policy, Eur. J. Agron., 16, 239-262, 2002.

Piñol, J., Beven, K., and Freer, J.: Modelling the hydrological response of Mediterranean catchments, Prades, Catalonia. The use of distributed models as aids to hypothesis formulation, Hydrol. Process., 11, 1287-1306, 1997.

Pulina, M. A.: L'Evapotraspirazione potenziale in Sardegna in funzione dello studio del regime idrico dei suoli. Studi sassaresi: organo ufficiale della Società sassarese di Scienze mediche e naturali, Vol. 32, Sez. 3: Annali della Facoltà di Agraria dell'Università di Sassari, Sassari, 96-109, 1986.

Senatore, A., Mendicino, G., Smiatek, G., and Kunstmann, H.: Regional climate change projections and hydrological impact analysis for a Mediterranean basin in Southern Italy, J. Hydrol., 399, 70-92, 2011.

Silvestro, F., Gabellani, S., Giannoni, F., Parodi, A., Rebora, N., Rudari, R., and Siccardi, F.: A hydrological analysis of the 4 November 2011 event in Genoa, Nat. Hazards Earth Syst. Sci., 12, 2743-2752, doi:10.5194/nhess-12-2743-2012, 2012.

Sulis, M., Paniconi, C., Rivard, C., Harvey, R., and Chaumont, D.: Assessment of climate change impacts at the catchment scale with a detailed hydrological model of surface-subsurface interactions and comparison with a land surface model, Water Resour. Res., 47, W01513, doi:10.1029/2010WR009167, 2011.

Sulis, M., Paniconi, C., Marroccu, M., Huard, D., and Chaumont, D.: Hydrologic response to multimodel climate output using a physically based model of groundwater/surface water interactions, Water Resour. Res., 48, W12510, doi:10.1029/2012WR012304, 2012.

Tramblay, Y., Ruelland, D., Somot, S., Bouaicha, R., and Servat, E.: High-resolution Med-CORDEX regional climate model simulations for hydrological impact studies: a first evaluation of the ALADIN-Climate model in Morocco, Hydrol. Earth Syst. Sci., 17, 3721-3739, doi:10.5194/hess-17-3721-2013, 2013.

Vivoni, E. R., Ivanov, V. Y., Bras, R. L., and Entekhabi, D.: Generation of triangulated irregular networks based on hydrological similarity, J. Hydrol. Eng., 9(, 288-302, doi:10.1061/(ASCE)1084-0699(2004)9:4(288), 2004.

Vivoni, E. R., Ivanov, V. Y., Bras, R. L., and Entekhabi, D.: On the effects of triangulated terrain resolution on distributed hydrologic model response, Hydrol. Process., 19, 2101-2122, doi:10.1002/hyp.5671, 2005.

Vivoni, E. R., Mascaro, G., Mniszewski, S., Fasel, P., Springer, E. P., Ivanov, V. Y., and Bras, R. L.: Real-world hydrologic assessment of a fully-distributed hydrological model in a parallel computing environment, J. Hydrol., 409, 483-496, doi:10.1016/j.jhydrol.2011.08.053, 2011.

Wilby, R. L. and Wigley, T. M. L.: Downscaling general circulation model output: A review of methods and limitations, Prog. Phys. Geogr., 21, 530-548, 1997.

Wood, A. W., Leung, L. R., Sridhar, V., and Lettenmaier, D. P.: Hydrologic implications of dynamical and statistical approaches to downscaling climate model outputs, Climatic Change, 62, 189216, 2004. 